\title{
An in situ kinetic study of brass dezincification and corrosion
}

\author{
P. Zhou ${ }^{\mathrm{a}}$, M. J. Hutchison ${ }^{\mathrm{b}}$, J.W. Erning ${ }^{\mathrm{c}}$, J. R. Scully ${ }^{\mathrm{b}}$, K. Ogle $\mathrm{a}^{\mathrm{a}}$.
}

\begin{abstract}
The kinetics of the anodic dissolution of brass $(\mathrm{CuZn} 42$ and $\mathrm{CuZn} 21 \mathrm{Si3P})$ in synthetic tap water were investigated by atomic emission spectroelectrochemistry. Elemental $\mathrm{Cu}$ and $\mathrm{Zn}$ dissolution rates were measured in situ and in real time during galvanostatic dissolution. A complete mass/charge balance for the system yielded, as a function of applied current and a function of time, the quantity of $\mathrm{Cu}$ in the dezincification layer and the quantity of $\mathrm{Cu}$ and $\mathrm{Zn}$ in the oxide layer. In this way, a complete kinetic characterization of the fundamental chemical processes occurring during dezincification was realized for the first time. The oxide layer was composed primarily of $\mathrm{Cu}_{2} \mathrm{O}$ as indicated by grazing incidence XRD and Raman analysis. The soluble $\mathrm{Cu}$ oxidation product was determined to be $\mathrm{Cu}$ (II) by a mass/charge balance. $\mathrm{Zn}$ was oxidized to soluble $\mathrm{Zn}$ (II) leaving behind a trivial amount of solid $\mathrm{Zn}$ corrosion product on the surface. The kinetic analysis depicts a two-stage dissolution process of dezincification: a first stage of a rapid growth of the dezincified layer and a second stage where the growth of dezincified layer was much slower. The $\mathrm{Cu}_{2} \mathrm{O}$ layer grows continually during the exposure.
\end{abstract}

\section{Introduction}

The corrosion process of brass often involves a mechanism of dezincification in which $\mathrm{Zn}$ is selectively dissolved leaving behind a porous metallic $\mathrm{Cu}$ enriched layer. Dezincificaiton is a major limiting factor for the use of brass in numerous applications and is also a model system for the selective dissolution of a binary alloy. It is not surprising that much attention has been paid to the mechanistic explanation of dezincification [1-14] and the characterization of the dezincification structure [15-18]. Numerous theories have been proposed, though, during the last decades, they can ultimately be categorized into two major groups: a mechanism of selective dissolution and a mechanism of dissolution-redeposition. As to the first group, theories such as volume diffusion of $\mathrm{Zn} \mathrm{[13]} \mathrm{and} \mathrm{/or} \mathrm{Cu}$ [14], surface diffusion [19], sometimes in conjunction with divacancy movement [4, 7-10, 20], as well as the percolation mechanism [21], are most representative. They depict a selective dissolution process of $\mathrm{Zn}$ without the electrochemical involvement of atomic $\mathrm{Cu}$. The dissolution-redeposition 

followed by a process of $\mathrm{Cu}$ plating back onto the surface, thus forming a defective metallic $\mathrm{Cu}$ layer.

A difficulty in identifying the underlying mechanisms of brass corrosion has been the fact that the oxidation of the brass, frequently measured as an anodic current in an electrochemical experiment, usually involves at least two different elements and results in both soluble and insoluble species. Various methods have been proposed to measure the partial dissolution rates of $\mathrm{Zn}$ and $\mathrm{Cu}$. Intermittent chemical analysis of $\mathrm{Cu}$ and $\mathrm{Zn}$ in the electrolyte was used by Pickering et al. [6-9], and the radioactive emissions of isotopes of $\mathrm{Zn}$ and $\mathrm{Cu}$ were followed by Polunin [10] and Pchelnikov et al. [21]. However, these methodologies have various drawbacks: intermittent electrolyte analysis neglects important transitional concentration changes, and the irradiation effect of radioactive indicators may cause the radiolysis of the electrolyte, thus affecting the corrosion process [22] and in any case, is only applicable to special alloys produced with isotopic $\mathrm{Cu}$ and $\mathrm{Zn}$.

Another problem is the complex nature of the oxide and zinc depleted metallic layers that are formed during corrosion. Most academic research of dezincification has been performed in acidic media where no oxide is formed [3, 23, 24]. However, the nearly neutral $\mathrm{pH}$ of tap water leads to a more complicated corrosion process and more severe dezincification [25] despite the lower corrosion rate. This dezincification severity and complexity is due to the formation of a multi-layered dezincification structure consisting of a $\mathrm{Zn}$ depleted layer and a corrosion product layer composed of $\mathrm{Zn}$ and $\mathrm{Cu}$ oxides [15, 16].

Conventional electrochemical methods such as potentiodynamic polarization $[15,26]$ and electrochemical impedance spectroscopy (EIS) $[15,26,27]$ have been used to predict the corrosion rate and to characterize the electrical properties of the interfacial structure. In situ techniques such as Raman spectroscopy [28], infrared reflection absorption spectroscopy (IRAS) [17], near normal incidence reflectance spectroelectrochemical technique (NNIRS) [29] and ultraviolet-visible (UV-vis) reflectance spectroscopy [16] can be used to observe the molecular identity of the oxide. But no quantitative kinetic information about $\mathrm{Cu}$ release into water, the growth of oxide layers, or the growth of the zinc depleted layer, has been obtained through these methods.

In this work the kinetics of dezincification are quantified using the atomic emission spectroelectrochemical (AESEC) methodology [31, 32]. This technique permits us to measure directly the rates of $\mathrm{Cu}$ and $\mathrm{Zn}$ dissolution in situ and in real time, and indirectly the rate of oxide and metallic $\mathrm{Cu}$ film formation. In a previous publication [30], we established the feasibility of using in situ AESEC [31, 32] to analyze copper dissolution in synthetic tap water in which a detailed quantitative relationship between the soluble 


\section{Experimental}

\section{$2.1 \quad$ Materials}

Brass discs of low-leaded CuZn42 and lead-free CuZn21Si3P of $\Phi 24 \mathrm{~mm} \times 2 \mathrm{~mm}$ were used in this work. Their elemental composition can be found in Table 1. Unless otherwise specified, samples for electrochemical experiments were dry ground up to P1200 (600 grit) silicon carbonate paper, rinsed with deionized water $\left(0.0549 \mu \mathrm{S} \mathrm{cm}^{-1}\right.$ at $\left.25{ }^{\circ} \mathrm{C}\right) \mathrm{using}$ a Millipore $^{\mathrm{TM}}$ system), degreased with acetone, ethanol, and then dried under flowing nitrogen.

Synthetic tap water (STW) [37] containing $\mathrm{MgSO}_{4} \cdot 7 \mathrm{H}_{2} \mathrm{O}\left(31.92 \mathrm{mg} \mathrm{L}{ }^{-1}\right.$ ), $\mathrm{NaHCO}_{3}$ (36.00 mg L $\mathrm{mg}^{-1}$ ), $\mathrm{CaCl}_{2} \cdot 7 \mathrm{H}_{2} \mathrm{O}\left(102.9 \mathrm{mg} \mathrm{L}{ }^{-1}\right.$ ), $\mathrm{Na}_{2} \mathrm{SO}_{4}\left(275.5 \mathrm{mg} \mathrm{L}^{-1}\right.$ ), was prepared utilizing deionized water, with a $\mathrm{pH}$ of $7.5 \pm 0.1$ and a conductivity of $479 \mu \mathrm{S} \mathrm{cm} \mathrm{cm}^{-1}$. Citrate buffer solution (CBS) was used to dissolve the solid corrosion products formed during dissolution in STW, it was prepared by adjusting the $\mathrm{pH}$ value of $0.1 \mathrm{M}$ citrate acid (AppliChem) solution to 4.9 \pm 0.1 , using $0.1 \mathrm{M}$ citrate trisodium solution (Amresco), and deaerated for at least $30 \mathrm{~min}$ with an argon bubbling system before use. 


\subsection{Dezincification test.}

The ISO 6509 dezincification test $[38,39]$ was performed in a $12.7 \mathrm{~g} \mathrm{~L}^{-1} \mathrm{CuCl}_{2}$ solution, with the sample being exposed to the electrolyte for 24 hours at $75 \pm 3{ }^{\circ} \mathrm{C}$ and then observed under optical microscope to measure the dezincification depth.

\subsection{Instrumentation}

The atomic emission spectroelectrochemistry (AESEC) technique was used to follow elemental dissolution kinetics during the corrosion and electrochemical polarization of brass. Details of this technique can be found in previous publications $[31,32,40] . \mathrm{Cu}$ dissolution was followed using a monochromator to detect the atomic $\mathrm{Cu}$ emission intensity at $324.75 \mathrm{~nm}$. Zn and $\mathrm{Si}$ were followed using a polychromator detecting the atomic emission intensity at $213.68 \mathrm{~nm}$ and $251.61 \mathrm{~nm}$ respectively. A conventional three-standard calibration was conducted for each element. The detection limit (LOD) was defined as three times the standard deviation of background noise divided by the sensitivity $(\alpha)$, which can be determined from the intensity - concentration calibration line. The LOD for $\mathrm{Cu}$ in STW and CBS was less than $1 \mathrm{ppb}$, for $\mathrm{Zn}$ it was $6 \mathrm{ppb}$ and for $\mathrm{Si}$ it was $17 \mathrm{ppb}$. A Gamry Reference $600^{\mathrm{TM}}$ potentiostat was used to control and/or measure the current and potential. The analog output of the potentiostat was routed into the data acquisition system of the ICP spectrometer so that spectroscopic intensity and electrochemical data were on an identical time scale.

A two compartment flow cell was used in this work with a reaction area of $A=1.0 \mathrm{~cm}^{2}$, and a flow rate $f=3.0 \mathrm{~mL} \mathrm{~min}^{-1}$. Details of the cell can be found elsewhere [31,32]. A platinum foil with an area of $5.0 \mathrm{~cm}^{2}$ was used as a counter electrode and a saturated calomel electrode (SCE) was used as reference electrode.

A PANalytical X'Pert X-ray Diffractometer using a Cu target $(\mathrm{K} \alpha=1.54 \AA)$ was used to analyze the sample following anodization at $80 \mu \mathrm{Am}^{-2}$ in STW. Grazing incidence X-ray diffraction (GIXRD) with an incidence angle $(\omega)$ of $0.5^{\circ}$ was performed on the oxidized sample. Bulk sample X-ray diffraction (XRD) was performed on a spinning stage.

A Renishaw InVia Raman microscope equipped with a Renishaw CCD camera detector was used to characterize the oxide composition: An Ar ion laser was used with and excitation line at $514 \mathrm{~nm}$ focused through a $50 \times 0.75 \mathrm{NA}$ objective, in conjunction with a grating of $1800 \mathrm{~g} / \mathrm{mm}$. Reference $\mathrm{Cu}_{2} \mathrm{O}$ spectra were obtained by analyzing the $\mathrm{Cu}_{2} \mathrm{O}$ powder (Sigma Aldrich).

A Zeiss Leo 1530 field emission scanning electron microscope (FE-SEM) was used to observe the surface morphology of brass samples after being exposed to STW. An in lens second electron detector was used to capture the image; the extra high tension (EHT) was fixed at $5 \mathrm{kV}$. 


\subsection{Electrochemical experiments and data analysis}

Anodic polarization of brass samples was conducted in STW at an applied current $\left(i_{a p}\right)$ ranging from 0 to $80 \mu \mathrm{A} \mathrm{cm} \mathrm{cm}^{-2}$ for $1200 \mathrm{~s}$, or with a time duration $(t)$ of $0 \mathrm{~s}, 300 \mathrm{~s}, 600 \mathrm{~s}$, $1200 \mathrm{~s}$ respectively at $i_{a p}=40 \mu \mathrm{A} \mathrm{cm} \mathrm{cm}^{-2}$. Before and after the polarization, a $300 \mathrm{~s}$ open circuit delay was also imposed respectively. After that, STW was replaced by CBS for a further open circuit dissolution of $1500 \mathrm{~s}$, aiming at dissolving the residual solid corrosion products on the surface.

A detailed description of the data analysis, including the conversion of the emission intensity profile into dissolution rate profile and the convolution of applied current, was given in a previous publication [30].

\section{Results}

\subsection{Dezincification test result.}

The ISO6509 accelerated corrosion test confirmed that the CuZn21Si3P was significantly less sensitive to dezincification as compared to CuZn42, Fig. 1. In the micrographs of Fig. $1 \mathrm{~A}$, the $\beta^{\prime}$ phase of $\mathrm{CuZn} 42$ shows a preferential dezincification as compared to the $\alpha$ matrix, with the dezincification front penetrating along the dezincified $\beta^{\prime}$ phase. As expected, the test of CuZn21Si3P (Fig. 1B) shows a better dezincification performance under identical test conditions, with an undetectable dezincification structure visible at the magnification of Fig. 1.

\subsection{Elemental dissolution behavior in synthetic tap water (STW)}

The differences in dezincification kinetics of the two alloys, exemplified by Fig. 1, is also apparent in the transient elemental dissolution rates during accelerated dezincification tests in synthetic tap water (Fig. 2). A typical full experiment is given in Fig. 2 for CuZn42 (A) and CuZn21Si3P (B) respectively. The experiment is divided into four stages: (a) an open circuit dissolution in STW for $300 \mathrm{~s}$; (b) a galvanostatic pulse for $1200 \mathrm{~s}$; (c) another open circuit dissolution for $300 \mathrm{~s}$; and finally, (d) dissolution of residual oxide films formed during $(\mathrm{a}-\mathrm{c})$ by exposure to CBS at open circuit dissolution for $1500 \mathrm{~s}$. Prior to $t=0 \mathrm{~s}$, the pure electrolyte was fed into the plasma permitting a measurement of the background intensity and detection limit for each element. These experiments were performed with either an applied anodic galvanostatic current ranging from 0 to $80 \mu \mathrm{A} \mathrm{cm}^{-2}$ for $1200 \mathrm{~s}$, or a time duration ranging from $\underline{0 \text { to }} 1200 \mathrm{~s}$ at $40 \mu \mathrm{A} \mathrm{cm}^{-}$ 2 .

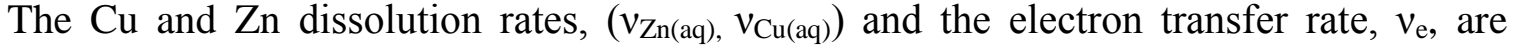
given as a function of time in Fig. 2. This type of presentation will be referred to as a dissolution profile. Also shown is the electron transfer rate convoluted with the hydrodynamic distribution of time constants in the flow cell, $v^{*}$. This corrects for the 
different time resolution between the electrochemical data which are essentially instantaneous, and the elemental dissolution rates which are broadened by mixing in the cell, capillaries, and nebulization system [42]. Also presented is the sum of the elemental dissolution, $v_{\Sigma}=v_{Z n(a q)}+v_{C u(a q)}$. This data set has been multiplied by a factor of 2 to facilitate comparison with $v_{\mathrm{e}}^{*}$ (see below.) Si dissolution was also detected, but it is not shown due to a poor signal to noise ratio.

The open circuit dissolution rates of $\mathrm{Zn}$ and $\mathrm{Cu}$ in STW were readily measured for both alloys, although it is not apparent on the scale of Fig. 2. An enlarged view of the open circuit dissolution STW is shown in Fig. 3A and 3B. The average open circuit dissolution rates for each alloy in STW (stage $a$ ) are listed in Table 2. Also listed in the table are the theoretical congruent dissolution rates of $\mathrm{Cu}$ and Si in STW and CBS, with reference to the experimental $\mathrm{Zn}$ partial corrosion rate, based on the component ratio of the bulk. For both alloys in STW (Table 2), the Cu partial corrosion rate is significantly lower than the congruent value calculated from the $\mathrm{Zn}$ dissolution rate. This rate discrepancy is indicative of a selective $\mathrm{Zn}$ dissolution process leaving behind either an oxidized $\mathrm{Cu}$ film or a metallic $\mathrm{Cu}$ layer.

It is of interest to compare this $\mathrm{Zn}$ selective leaching with that observed in the CBS electrolyte directly at the end of the experiment, (stage $d$ in Fig. 2). This data is also given in Table 2. In this case, the $\mathrm{Cu}$ dissolution rate was equivalent to or slightly higher than the estimated congruent dissolution rate indicating that $\mathrm{Cu}$ corrosion products were soluble in this electrolyte.

Insight into the formation of oxide films during the galvanostatic pulse may be derived from a quantitative consideration of the dissolution rates as compared to the electron transfer rate during the anodic stage b of Fig. 2. The sum of the elemental dissolution rates is well below the electron exchange rate, $v_{e}$, even when the former is multiplied by 2 , the highest valence that one would reasonably expect for either $\mathrm{Cu}$ or $\mathrm{Zn}$ in this electrolyte. The difference between the oxidative electron transfer and elemental dissolution may be explained by the formation of insoluble oxidized $\mathrm{Cu}$ and/or $\mathrm{Zn}$ species since no other significant oxidation reactions would be expected in this electrolyte at the potentials used.

Fig. 4 shows the superimposition of $\mathrm{Cu}$ and $\mathrm{Zn}$ dissolution at various galvanostatic currents. A remarkable feature of the $\mathrm{Zn}$ dissolution profiles shown in this figure is the transient response to the anodic polarization, leading to a rapid increase in the $\mathrm{Zn}$ dissolution rate, which decreased gradually throughout the remainder of the anodic pulse. This curious behavior coincides with the results observed by Pchelnikov [11] using Zn isotopes and Pickering [6] using quantitative chemical analysis of the electrolyte. The $\mathrm{Cu}$ dissolution rate, however, increased gradually, though at different rates for different alloys: for $\mathrm{CuZn42,} \mathrm{a} \mathrm{sluggish} \mathrm{increase} \mathrm{of} \mathrm{Cu}$ dissolution rate was observed with no 

state dissolution rate was reached after about $300 \mathrm{~s}$ after the initiation of anodic polarization. This was followed by a rapid decrease (stage $c$ ), identical for both alloys. Also, for $\mathrm{CuZn42,} \mathrm{during} \mathrm{the} \mathrm{first} \mathrm{few} \mathrm{seconds} \mathrm{of} \mathrm{the} \mathrm{anodization,} \mathrm{no} \mathrm{soluble} \mathrm{Cu}$ species were detected, while $\mathrm{Zn}$ dissolution increased rapidly. This period will be referred to as an induction period. The induction period was not observed on $\mathrm{CuZn} 21 \mathrm{Si3P}$.

\subsection{Analysis of insoluble corrosion products}

The formation of insoluble corrosion products during the galvanostatic pulse was clearly demonstrated by the significant mismatch between the sum of the elemental dissolution rates and the electrical current (stage $b$ in Fig. 2The feasibility of using CBS to dissolve insoluble copper corrosion products with minimal corrosion of the substrate was previously demonstrated [30]. In this paper, the same methodology was used. Dissolution profiles of the corrosion products in deaerated CBS electrolyte are given in Fig. 5. The integral of the $\mathrm{Cu}$ and $\mathrm{Zn}$ dissolution transients in Fig. 5, gives the total amount of each element in the corrosion product film present at the surface following the exposure to $\mathrm{STW}$, referred to as $\mathrm{Q}_{\mathrm{Cu}}(\mathrm{CBS})$ and $\mathrm{Q}_{\mathrm{Zn}}(\mathrm{CBS})$. It is clear from the figure that the corrosion product layer was mainly composed of $\mathrm{Cu}$ oxides [46], with $\mathrm{Zn}$ oxide and/or hydroxides as a minor constituent. The value of $\mathrm{Q}_{\mathrm{Zn}}(\mathrm{CBS})$ showed no statistically significant variation in quantity with either galvanostatic time or current [45-46].

To further verify that the dissolution waves of $\mathrm{Cu}$ and $\mathrm{Zn}$ were from the dissolution of the oxides rather than the dissolution of the substrate, a reference experiment was conducted with a fresh brass sample in deaerated CBS, curve $a$ in Fig. 5. For CuZn42, a large peak of $\mathrm{Zn}$ and a negligible peak of $\mathrm{Cu}$ were observed when exposed to CBS for a few seconds. For $\mathrm{CuZn} 21 \mathrm{Si3P}$, relatively comparable peaks of $\mathrm{Cu}$ and $\mathrm{Zn}$ were observed. These peaks were significantly different from the dissolution wave of the alloys after STW exposure, and demonstrate that neither the substrate nor the metallic component of the dezincification layer contribute significantly to the dissolution profiles of curve $b$ - $g$. Note that the quantity of $\mathrm{Cu}_{-}$is negligible in curve a as compared to the other experiments so it is safe to ignore the corrosion of the substrate during the determination of the quantity of residual oxides.

For both CuZn42 and CuZn21Si3P, a salmon colored layer was visually observable after removal of the oxide layer by $\mathrm{CBS}$. This layer corresponded to the $\mathrm{Zn}$ depleted metallic $\mathrm{Cu}$ layer which was not soluble in $\mathrm{CBS}$. The presence of this metallic $\mathrm{Cu}$ film affected the steady state open circuit dissolution rates in CBS (Table 2). For the reference experiments with freshly ground samples (no preexisting oxide layer) both alloys show a slight preferential dissolution of $\mathrm{Zn}$ as compared to their bulk composition (curve $a$ in Fig. 5). This was much less significant than in STW due no doubt to the solubility of the solid 
$\mathrm{Cu}$ oxidation products. However, when the alloy had been subjected to a galvanostatic treatment, the corrosion rate in CBS after oxide dissolution, yielded a $\mathrm{Cu}$ dissolution rate larger than that predicted for congruent dissolution attributed to the excess $\mathrm{Cu}$ content of the material exposed to the electrolyte. Nevertheless, the $\mathrm{Zn}$ dissolution rate did not appear to be affected, indicating that the dezincification layer did not significantly protect the underlying substrate from corroding.

\subsection{Characterization of residual oxides}

The residual oxide film formed on pure $\mathrm{Cu}$ in STW was almost entirely composed of $\mathrm{Cu}_{2} \mathrm{O}$ as demonstrated in [30]. To verify whether or not this was the case for the brass samples, GIXRD and Raman spectrometry were used to analyze the oxide layer formed after anodic polarization at various applied current for 1200 s. Fig. 6 presents the GIXRD results of both alloys with pure $\mathrm{Cu}$ as a reference [30]. Consistent with the case of pure $\mathrm{Cu}$, crystallized $\mathrm{Cu}_{2} \mathrm{O}$ was detected on both alloys after anodic polarization. However, no peaks corresponding to a pure $\mathrm{Cu}$ dezincified layer could be detected by GIXRD as would be evidenced by $\mathrm{Cu}$ fcc lattice peaks shifted due to the change in lattice parameter from lack of substitutional $\mathrm{Zn}$, even though the $\mathrm{Cu}$ film was visually observable. Similarly, the Raman spectra (Fig. 7) show peaks at $150 \mathrm{~cm}^{-1}, 220 \mathrm{~cm}^{-1}, 411$ $\mathrm{cm}^{-1}$ and $650 \mathrm{~cm}^{-1}$ supporting the existence of $\mathrm{Cu}_{2} \mathrm{O}$. Nonetheless, the existence of $\mathrm{CuO}$ cannot be excluded since the Raman shift of $\mathrm{CuO}$ at $633 \mathrm{~cm}^{-1}$ is very close to that of $\mathrm{Cu}_{2} \mathrm{O}$ at $635 \mathrm{~cm}^{-1}$ [41-43]. Moreover, it is possible that some thin amorphous $\mathrm{CuO}$ species cannot be detected by GIXRD or Raman spectroscopy [43]. The Raman shift at $525 \mathrm{~cm}^{-1}$ was due to $\mathrm{Cu}-\mathrm{OH}$ vibration in defective $\mathrm{Cu}_{2} \mathrm{O}$ [44]. It is thermodynamically possible that some $\mathrm{Cu}_{2} \mathrm{O}$ can be further oxidized into $\mathrm{CuO}$ by exposure to air. However, since neither GIXRD nor Raman spectroscopy detected any $\mathrm{Cu}(\mathrm{II})$ species, it is reasonable to conclude that even if $\mathrm{CuO}$ exists at the surface, its quantity is still far smaller than the $\mathrm{Cu}_{2} \mathrm{O}$ in the surface oxide film.

\subsection{Surface morphology}

Based on the previous analysis, it's clear that cuprite $\left(\mathrm{Cu}_{2} \mathrm{O}\right)$ is the primary solid corrosion product deposited on the surface. The distribution of the corrosion product on the surface was investigated by SEM observations of the brass samples before and after exposure to STW at $i_{a p}=5 \mu \mathrm{A} \mathrm{cm}^{-2}$ and $t=1200 \mathrm{~s}$ (Fig. 8-9). Note that samples used for SEM observation were polished to $1 \mu \mathrm{m}$ diamond paste to a mirror finish. Such a low current was chosen to enable the formation of $\mathrm{Cu}$ oxides among different phases after the induction period, as is shown in Fig. 4 (A). Further, a larger applied current will produce more oxide film on the surface, thus covering the surface, making it difficult to differentiate the different metallurgical phases. For these samples, the oxide layer of $\mathrm{CuZn} 42$ was formed in the center of the reacting zone, and the layer of CuZn21Si3P was | evenly distributed on the exposure area. Only the region which shows a complete coverage of oxide film was observed by SEM. Both figures show cubic solid crystalline 
products distributed on the surface. These cubic-shaped crystals were assumed to be $\mathrm{Cu}_{2} \mathrm{O}$ based on GIXRD and Raman analysis. However, the distribution of cubic $\mathrm{Cu}_{2} \mathrm{O}$ on the surface is completely different among the two alloys: in Fig. 8, cubic crystals were evenly formed on the surface and no clear sign of preferential deposition of $\mathrm{Cu}_{2} \mathrm{O}$ on the different metallographic phase structures was found, with respect to the duplex structure of $\mathrm{CuZn} 42$. However, the distribution of $\mathrm{Cu}_{2} \mathrm{O}$ on $\mathrm{CuZn} 21 \mathrm{Si3P}$ shows a remarkable preferential distribution: in Fig. 9, a clear crystal boundary based on the distribution of $\mathrm{Cu}_{2} \mathrm{O}$ can be distinguished. In fact, more than $50 \%$ of the area was covered with evenly distributed cubic particles, and the other half showed a lower density of $\mathrm{Cu}_{2} \mathrm{O}$ cubic particles with incomplete coverage.

\subsection{Mass and Charge Balance}

The quantity of the $\mathrm{Cu}$ oxide and of the residual metallic $\mathrm{Cu}$ layer as a function of time may be determined from a detailed mass/charge balance for the dissolution of $\mathrm{Cu}$ and $\mathrm{Zn}$ during the STW experiments. This requires knowledge of the oxidation states of the corrosion products. Based on the previous surface characterization, it's reasonable to assume that brass dissolution in STW leads primarily to the formation of aqueous $\mathrm{Cu}$ (II) species and solid $\mathrm{Cu}_{2} \mathrm{O}$, identical to the case of pure copper [30]. Zn dissolution of course occurs via the formation of aqueous $\mathrm{Zn}$ (II) species leaving behind a trivial amount of precipitated $\mathrm{Zn}$ (II) as an amorphous $\mathrm{Zn}$ oxide or $\mathrm{Zn}$ hydroxide [45-48]. These solid $\mathrm{Zn}$ species remained on the surface and were independent of galvanostatic current and time, as is shown in Fig. 5. The $\mathrm{Si}$ in CuZn21Si3P was assumed to be oxidized into $\mathrm{Si}$ (IV) species_[49], although the quantity was low and does not significantly contribute to the total charge.

The validity of these assumptions- that the corrosion products consists of $\mathrm{Cu}(\mathrm{II})$ and $\mathrm{Zn}$ (II) aqueous and $\mathrm{Cu}(\mathrm{I})$ solid species- may be verified by comparing the total quantity of electricity, $Q_{e}$ (pstat) during the galvanostatic pulse, with the total equivalent electricity from the calculated from the elemental dissolution rates, $Q_{e}(I C P)$.

$$
Q_{e}(I C P)=\sum n_{m, a q} Q_{m, a n(a q)}+\sum n_{m, s} Q_{m, a n(s)}
$$

where $Q_{m, a n}$ represents the quantity of elemental dissolution of a metal, $m(\mathrm{Cu}, \mathrm{Zn}$ and $\mathrm{Si})$, contributed to either aqueous species $(a q)$ or solid species (s), and $n_{m, a q}, n_{m, s}$ are the valence of each species in the form of aqueous or solid state. The two terms on the right of eq. $1, Q_{m, a n(a q)}$ and $Q_{m, a n(s)}$, are the net quantity of aqueous and solid species attributed to the galvanostatic pulse, which can be further calculated through eq. 2-3.

$$
\begin{aligned}
& Q_{m, a n(a q)}=Q_{m}(S T W)-Q_{m}(S T W)\left(i_{a p}=0\right) \\
& Q_{m, a n(s)}=Q_{m}(C B S)-Q_{m}(C B S)\left(i_{a p}=0\right)
\end{aligned}
$$


where $Q_{m}(S T W)$ and $Q_{m}(C B S)$ correspond to the total quantities of elemental dissolution of $m$ during the STW or CBS period. These values are determined by integration of the dissolution profiles. The quantity of elemental species formed during the open circuit exposure must be removed from this value in order to obtain the correct mass balance. In equation $2 \& 3$ this background mass was assumed to be given by $Q_{m}(S T W)\left(i_{a p}=0\right)$ and $Q_{m}(C B S)\left(i_{a p}=0\right)$, the quantity of aqueous species of element $m$ in STW, when $i_{a p}=0$. The subtraction of these terms from $Q_{m}(S T W)$ and $Q_{m}(C B S)$ provides a net quantity of each species produced by the galvanostatic current, since all the experiments were performed on an identical time scale.

The comparison between $Q_{e}(I C P)$ and $Q_{e}$ (pstat) at various applied current or various time duration was shown in Fig. $10 \mathrm{~A}$ and B. The experimental data fits the $Q_{e}(I C P)=$ $Q_{e}$ (pstat) (dashed line) fairly well within experimental error, though some deviation is observed at higher current, which may be due to the errors in background subtraction discussed above, or perhaps the existence of a trace amount of solid $\mathrm{Cu}(\mathrm{II})$ species. Nevertheless, the relatively good agreement of experimental points with the $Q_{e}(I C P)=$ $Q_{e}$ (pstat) line corroborates the assumption of the oxidization state of each element in the aqueous and the solid phase.

\subsection{Growth of the dezincification and the oxide layers}

It is of great mechanistic interest to investigate the rates of formation of aqueous $\mathrm{Cu}^{2+}$, the solid $\mathrm{Cu}_{2} \mathrm{O}$ corrosion product layer, and the $\mathrm{Zn}$ depleted metallic copper layer as a function of applied current or time. Fig. 11 gives the values of $Q_{C u}(S T W)$ representing the quantity of $\mathrm{Cu}$ dissolved, and $Q_{C u}(C B S)$ representing the quantity of solid $\mathrm{Cu}_{2} \mathrm{O}$ oxide formed, plotted as a function of applied current for both alloys. In all cases the $\mathrm{Cu}_{2} \mathrm{O}$ formation is clearly favored over $\mathrm{Cu}^{2+}$ dissolution, as was observed for pure $\mathrm{Cu}$ dissolution under identical experimental conditions [30]. Also, the growth rate of $\mathrm{Cu}_{2} \mathrm{O}$ oxide film on both alloys decreased with the increase of $i_{a p}$, while the growth rate of $\mathrm{Cu}^{2+}$ began to increase at higher current.

The establishment of mass/charge balance calculation allows us to estimate the thickness of the dezincified layer, assuming a compact pure $\mathrm{Cu}$ layer sandwiched by the outermost $\mathrm{Cu}_{2} \mathrm{O}$ layer and the brass substrate. The thickness of the dezincified layer $\left(\delta_{C u}\right)$ and residual oxide film $\left(\delta_{\mathrm{Cu}_{2} \mathrm{O}}\right)$ can be estimated through eq. 4-5:

$$
\delta_{C u}=\frac{M_{C u}\left\{\alpha\left[Q_{Z n}(S T W)+Q_{Z n}(C B S)\right]-\left[Q_{C u}(S T W)+Q_{C u}(C B S)\right]\right\}}{\rho_{C u}}
$$

$$
\delta_{C u 2 O}=M_{C u 2 O} \frac{Q_{C u(a q)}(C B S)}{\rho_{C u 2 O}}
$$


where $\alpha$ represents the molar ratio of $\mathrm{Cu} / \mathrm{Zn}$ in the bulk; $\rho_{C u}$ and $\rho_{C u 2 O}$ are the density of each component assuming that the dezincified layer and the corrosion product layer are both compact and dense; $M_{C u}$ and $M_{C u 2 O}$ are the molar mass for each component. The growth of $\delta_{\mathrm{Cu}}$ and $\delta_{\mathrm{Cu}_{2} \mathrm{O}}$ as a function of the applied current are presented in Fig. 12 assuming a $\rho_{C u}=8.90 \mathrm{~g} \mathrm{~cm}^{-3}$ and $\rho_{\mathrm{Cu}_{2} \mathrm{O}}=6.04 \mathrm{~g} \mathrm{~cm}^{-3}$. This calculation definitely underestimates the thickness of the pure $\mathrm{Cu}$ layer and the $\mathrm{Cu}_{2} \mathrm{O}$ layer, considering the porous structures of both. However, the growth of both layers with the increase of applied current signifies that both the dezincified layer and the oxide layer thicken with current.

Also shown in Fig. 12 is the dezincification factor ( $\mathrm{Z}$ factor), eq. 6 [5]:

$$
Z=\frac{(Z n / C u)_{\text {oxidized }}}{(Z n / C u)_{\text {metal }}}=\alpha \frac{Q_{Z n(a q)}(S T W)+Q_{Z n(a q)}(C B S)}{Q_{C u(a q)}(S T W)+Q_{C u(a q)}(C B S)}
$$

From this definition, $Z=1$ would represent perfect congruent dissolution. $Z>1$ represents a preferential dissolution of $\mathrm{Zn}$, the degree of which is quantified by the magnitude of $Z$. Fig. 12 shows clearly that the $Z$ factor decreases rapidly with increasing current for $i_{a p}<20 \mu \mathrm{A} \mathrm{cm}^{-2}$, and approaches $Z=1.5$ for $i_{a p}>20 \mu \mathrm{A} \mathrm{cm}^{-2}$. CuZn21Si3P has a smaller $\mathrm{Z}$ than $\mathrm{CuZn} 42$ at various current values, which corroborates the ISO dezincification test result, as is shown in Fig. 1.

Also in Fig. 12, $\delta_{C u}$, increased linearly with increasing applied current for each alloy. This result contrasts with that of Pchelnikov [11] who reported that on an $\alpha$-brass, the dezincified layer was independent of time and applied current. This result lead him to conclude that a dissolution / redeposition mechanism was operative as the steady state thickness would require both dissolution and redeposition.

\section{Kinetic analysis and Discussion}

The results presented here demonstrate that the primary reactions involved in the corrosion of brass in tap water are as follows:

$$
\begin{array}{ll}
\mathrm{Zn} \rightarrow \mathrm{Zn}^{2+}(a q)+2 e^{-} & 7 . \\
\mathrm{Cu} \rightarrow \mathrm{Cu}^{+}(a q)+e^{-} & 8 . \\
2 \mathrm{Cu}^{+} \underline{(a q)}+\mathrm{H}_{2} \mathrm{O} \rightarrow \mathrm{Cu}_{2} \mathrm{O}(s)+2 \mathrm{H}^{+} & 9 .
\end{array}
$$

The formation of the $\mathrm{Cu}$ rich dezincification layer may be attributed to one of two broad classes of mechanisms: 1) redeposition due to the oxidation of $\mathrm{Zn}$ with $\mathrm{Cu}^{2+}$ or the disproportionation of $\mathrm{Cu}_{2} \mathrm{O}$ [1], or 2) a selective dissolution of $\mathrm{Zn}$ via a surface diffusion [19] or percolation mechanism [21]. Insight into the mechanism of dealloying may be gained via a time resolved kinetic analysis of the elemental dissolution and film growth. 

galvanostatic pulse is shown in Fig. 13. In this figure, the $v_{C u(a q)}, v_{Z n(a q)}$ are the direct dissolution profiles from ICP-OES. The growth rate of oxide film, $v_{C u 2 O}$, and the dezincified layer, $v_{C u}$, was calculated via eq. 10-11.

$$
\begin{array}{cc}
v_{C u 2 O}=\left[v_{e}^{*}-\sum v_{m(a q)}(S T W)\right] / 2 & 10 . \\
v_{C u}=\alpha v_{Z n(a q)}(S T W)-2 v_{C u 2 O}(S T W)-v_{C u(a q)}(S T W) & 11 .
\end{array}
$$

where $v_{e}^{*}$ is the convoluted electrical current, $\sum v_{m(a q)}$ is the sum of elemental dissolution rates, such as $v_{C u(a q)}(S T W), v_{Z n(a q)}(S T W)$ and $v_{S i(a q)}(S T W), \alpha$ is the molar ratio of $\mathrm{Zn} / \mathrm{Cu}$ in the bulk material. Also, the instantaneous dezincification factor, $Z$, as a function of time, is presented in this figure to demonstrate the instantaneous dezincification severity.

In Fig. 13, the dashed curves represent the convoluted electrical current, normalized to the steady state value of each component. If dissolution and film growth followed directly the applied current, that is to say the rate increased in an instantaneous step to the steady state, it would be expected to follow this curve. The convolution of the current accounts for the broadening of the measured result due to mixing in the flow cell.

The $\mathrm{Zn}$ dissolution rate increases very rapidly at the application of anodic current and actually passes through a maximum during the early stages of the experiment. In contrast, the $\mathrm{Cu}$ dissolution rate increases slowly only reaching steady state after several minutes. The increase of the $\mathrm{Cu}_{2} \mathrm{O}$ film is in fairly good agreement with the convoluted current while the formation of the metallic $\mathrm{Cu}$-rich dealloyed layer (dezincified zone) shows an intense peak during the early period and drops off to a near zero value.

These results are consistent with the hypothesis that, at $t=0, \mathrm{Zn}$ is oxidized more readily than $\mathrm{Cu}$ and a certain degree of $\mathrm{Zn}$ depletion must occur before $\mathrm{Cu}$ will oxidize directly to soluble $\mathrm{Cu}(\mathrm{II})$. Initially, $\mathrm{Cu}$ oxidation occurs via the formation of $\mathrm{Cu}_{2} \mathrm{O}$. $\mathrm{Cu}$ dissolution increases slowly as Zn depletion occurs, reaching a steady state only when the $\mathrm{Cu}$ film (dezincified layer) has also obtained a steady state configuration.

The selective dissolution of Zn was observed under all experimental conditions in STW, that is to say that the release of soluble $\mathrm{Zn}$ species (eq. 7) occurred more rapidly than the release of soluble $\mathrm{Cu}$ species (eq. 8), irrespective of the $\mathrm{Cu}$ to $\mathrm{Zn}$ ratio of the brass. When an anodic current was applied, a clear preferential formation of $\mathrm{Cu}_{2} \mathrm{O}$ on the surface was observed on both alloys, especially in the lower current region. So, in the corrosion of $\mathrm{Cu}-\mathrm{Zn}$ alloys, most $\mathrm{Cu}$ being oxidized will be present in the form of an oxide film; $\mathrm{Zn}$ is oxidized into both $\mathrm{Zn}$ soluble species that are released into STW and relatively small amounts of insoluble oxides / hydroxides that are deposited on the surface. 
Under the conditions of the AESEC system, CuZn21Si3P has a better corrosion resistance (Table 2) and dezincification resistance (Fig. 12), especially at low anodic current $\left(i_{a p} \leq 10 \mu \mathrm{A} \mathrm{cm} \mathrm{cm}^{-2}\right)$. This may be attributed to the absence of the high zinc containing $\beta^{\prime}$ phase.

Nevertheless, the anodic dissolution transients of $\mathrm{Cu}$ and $\mathrm{Zn}$ in STW for the two alloys differ markedly from each other. This may likewise be attributed to the differences in their metallurgical phases. It is well known that the $\beta$ ' phase in brass is more sensitive to dezincification, due to the higher solubility of $\mathrm{Zn}$ in solid solution. The dezincification of $\alpha, \beta$ '-brass initiates firstly on the $\beta$ ' phase [50], and propagates along the crystal boundary or dislocations $[2,51]$, since the $\beta$ ' phase has a corrosion potential of $180 \mathrm{mV}$ more negative than the $\alpha$ phase [52]. However, the SEM observation didn't show a clear composition contrast on CuZn42 that was due to the differentiation of dissolution rate among $\alpha$ and $\beta^{\prime}$ phase. On the contrary, the contrast may be observed on CuZn21Si3P, which is not only due to the preferential distribution of $\mathrm{Cu}_{2} \mathrm{O}$ particles, the chemical composition of the underlying phases must have changed significantly. Seuss et al [1] reported that in the exposure of $\mathrm{CuZnSi3P}$ to aggressive tap water, $\kappa$ phase shows a corrosion potential of more than $50 \mathrm{mV}$ more negative than $\alpha$ phase, $\gamma$ phase has a value of $100 \mathrm{mV}$ more negative than $\kappa$ phase. This means that more severe dissolution occurred on some metallurgical phases. However, the average corrosion rate of $\mathrm{CuZn21Si3P}$ was still lower than CuZn42. This can be explained by a relatively small proportion of less noble phases in the $\mathrm{CuZnSi} 3 \mathrm{P}$ matrix. It is reasonable to conclude that the difference in the dezincification performance was a direct result of the metallurgical phase difference. The $\gamma$ phase, even the $\kappa$ phase may contribute to the release of $\mathrm{Cu}^{2+}$ into tap water, also in turn promoting the formation of $\mathrm{Cu}$ oxides.

The kinetic analysis shown in Fig. 13 demonstrates that the anodic dissolution of brass comprises two stages: a first stage where a growth peak of the dezincified layer can be found during the initial period of the galvanostatic pulse; and a second stage where the growth peak decreases to a very low rate, indicating a simultaneous dissolution of $\mathrm{Cu}$ and $\mathrm{Zn}$ or at least a less severe preferential dissolution of $\mathrm{Zn}$, since the $\mathrm{Z}$ factor in this stage is close to 2 (Fig. 13). Among the two alloys, obviously CuZn42 shows a more intense growth of the dezincified layer consistent with the accelerated test results of Fig. 1.

The two-stage phenomenon found in the anodic dissolution of brass seems to support the dissolution-redeposition mechanism $[2,5,10,11]$. However, considering the complex metallurgical structure of the alloys investigated, the non-clarity as to the oxidation process of $\mathrm{Cu}$ to $\mathrm{Cu}_{2} \mathrm{O}$ and $\mathrm{Cu}^{2+}$ species, and the possibility of galvanic corrosion among different metallurgical phases, a detailed conclusion regarding the mechanism is still yet to be made. Further work with pure phase samples of $\alpha$ brass and $\beta^{\prime}$ brass is in progress so as to address these questions. 


\section{Conclusions}

In this work, the dezincification kinetics of two commercial brass samples, CuZn42 and CuZn21Si3P, were investigated.

1. The main products of the anodic dissolution of brass in synthetic tap water (STW) were soluble $\mathrm{Cu}$ (II) and $\mathrm{Zn}$ (II) species, and a solid $\mathrm{Cu}_{2} \mathrm{O}$ film. A $\mathrm{Zn}$ depleted metallic $\mathrm{Cu}$ film was formed due to the selective dissolution (dezincification) of $\mathrm{Zn}$.

2. The partial dissolution rates of $\mathrm{Cu}$ and $\mathrm{Zn}$ as a function of time throughout the exposure of brass to a synthetic tap water solution were established. Zn dissolution was significantly enhanced during the first stages of the exposure indicative of a dezincification reaction.

3. The rates of formation of the $\mathrm{Cu}_{2} \mathrm{O}$ layer and the $\mathrm{Zn}$ depleted metallic $\mathrm{Cu}$ layer were determined as a function of time via a mass/charge balance.

4. $\mathrm{Cu}$ oxidation during the early stages of the galvanostatic pulse formed $\mathrm{Cu}_{2} \mathrm{O}$; the rate of soluble $\mathrm{Cu}$ (II) formation increased slowly with time.

5. The dezincified layer grew rapidly during the early stages but slowed to almost zero at longer times as the rate of $\mathrm{Cu}$ dissolution increased.

6. The overall kinetic picture was similar for the two brass samples, however the CuZn42, a duplex ( $\alpha, \beta$ '-brass) showed a significantly more intense dezincification rate which was attributed to the presence of the $\beta^{\prime}$ phase with high $\mathrm{Zn}$ content.

\section{Acknowledgement:}

The authors would like to express their thanks to Dr. Fan Sun for his helpful advice on the SEM observation; we also express our sincere gratitude to Ms. Alina Maltseva for assistance with Raman spectroscopy. Two of the authors (JRS and MJH) were partially supported by the US National Science Foundation under DMR-130999 and U.S. Office of Naval Research under Grant SP0028970-PROJ0007990. 


\section{References}

[1] F. Seuss, N. Gaag, S. Virtanen, Corrosion mechanism of CuZn21Si3P in aggressive tap water. Materials and Corrosion (2016) DOI: 10.1002/maco.201609018.

[2] H. Sugawara, H. Ebiko, Dezincification of Brass, Corrosion Science 7 (1967) 513523.

[3] L. Burzyńska, Comparison of the spontaneous and anodic processes during dissolution of brass, Corrosion Science 43 (2001) 1053-1069.

[4] H. Lu, K. W. Gao, W. Y. Chu, Determination of tensile stress induced by dezincification layer during corrosion for brass, Corrosion Science 40 (1998) 1663-1670.

[5] R. H. Heidersbach, E. D. Verink, The dezincification of alpha and beta brasses, Corrosion 28 (1972) 397-418.

[6] H. W. Pickering, P. J. Byrne, Partial currents during anodic dissolution of Cu-Zn alloys at constant potential, Journal of the Electrochemical Society 116 (1969) 1492-1496. [7] H. W. Pickering, P. J. Byrne, On preferential anodic dissolution of alloys in the lowcurrent region and the nature of the critical potential, Journal of the Electrochemical Society 118 (1971) 209-215.

[8] H. W. Pickering, Volume diffusion during anodic dissolution of a binary alloy, Journal of the Electrochemical Society 115 (1968) 143-147.

[9] H. W. Pickering, Electrolytic dissolution of binary alloys containing a noble metal. Journal of the Electrochemical Society 114 (1967) 698-706.

[10] A. V. Polunin, A. P. Pchelnikov, V. V. Losev, I. K. Marshakov, Electrochemical studies of the kinetics and mechanism of brass dezincification, Electrochimica Acta 27 (1982) 467-475.

[11] A. P. Pchelnikov, A. D. Sitnikov, I. K. Marshakov, V. V. Losev, A study of the kinetics and mechanism of brass dezincification by radiotracer and electrochemical methods, Electrochimica Acta 26 (1981) 591-600.

[12] W. C. Fort, Mechanisms and inhibition of dealloying in an alpha brass, Ph. D dissertation, University of Florida, 1975.

[13] B. Assouli, A. Srhiri, and H. Idrissi, Characterization and control of selective corrosion of $\alpha, \beta^{\prime}$-brass by acoustic emission, NDT \& E International 36 (2003) 117126.

[14] R. C. Newman, T. Shahrabi, K. Sieradzki, Direct electrochemical measurement of dezincification including the effect of alloyed arsenic, Corrosion science 28 (1988) 873886.

[15] M. B. Valcarce, S. R. de Sanchez, M. Vazquez, Brass dezincification in a tap water bacterial suspension, Electrochimica Acta 51 (2006) 3736-3742.

[16] M. B. Valcarce, S. R. De Sanchez, M. Vazquez, A comparative analysis of copper and brass surface films in contact with tap water, Journal of Materials Science 41 (2006) 1999-2007.

[17] P. Qiu, C. Leygraf, Initial oxidation of brass induced by humidified air, Applied Surface Science 258 (2011) 1235-1241. 
[18] T. L. Barr, J. J. Hackenberg, Determination of the onset of the dezincification of alpha-brass using x-ray photoelectron (ESCA) spectroscopy, Journal of the American Chemical Society 104 (1982) 5390-5394.

[19] A. J. Forty, G. Rowlands, A possible model for corrosion pitting and tunneling in noble-metal alloys, Philosophical Magazine A, 43 (1981) 171-188.

[20] H. W. Pickering, C. Wagner, Electrolytic dissolution of binary alloys containing a noble metal, Journal of the Electrochemical Society 114 (1967) 698-706.

[21] K. Sieradzki, R. R. Corderman, K. Shukla, R. C. Newman, Computer simulations of corrosion: selective dissolution of binary alloys. Philosophical Magazine A 59 (1989) 713-746.

[22] Y. M. Kolotyrkin, Use of radioactive indicator and electrochemical methods for determining low corrosion rates, Electrochimica Acta 18 (1973) 593-606.

[23] R. K. Dinnappa, S. M. Mayanna, The dezincification of brass and its inhibition in acidic chloride and sulphate solutions, Corrosion Science 27 (1987) 349-361.

[24] Q. Liu, H. Luo, C. F. Dong, K. Xiao, X. G. Li, The electrochemical behavior of brass in $\mathrm{NaHSO}_{3}$ solution without and with $\mathrm{Cl}^{-}$. International Journal of Electrochemical Science 7 (2012) 11123-11136.

[25] Y. Feng, W. K. Teo, K. S. Siow, A. K. Hsieh, The corrosion behavior of copper in neutral tap water. Part II: Determination of corrosion rates Corrosion Science 38 (1996) 387-395.

[26] S. M. Awadh, F. M. A. Kharafi, B. G. Ateya, Selective dissolution of alpha brass in acid noncomplexing media, Journal of the Electrochemical Society 156 (2009) C114-

C121.

[27] K. Satendra, T. S. N. Sankara Narayanan, M. Suresh Kumar, A. Manimaran, Dezincification of brass in sulfide polluted sodium chloride medium: evaluation of the effectiveness of 2-mercaptobenzothiazole, International Journal of Electrochemical Science 1 (2006) 456-469.

[28] J. C. Rubim, Surface enhanced Raman scattering (SERS) from benzotriazole adsorbed on brass electrodes, Chemical Physics Letters 167 (1990) 209-214.

[29] B. S. Kim, T. Piao, S. N. Hoier, S. M. Park, In situ spectro-electrochemical studies on the oxidation mechanism of brass, Corrosion Science 37 (1995) 557-570.

[30] P. Zhou, M. J. Hutchison, J.R. Scully, K. Ogle, The anodic dissolution of copper alloys: Pure copper in synthetic tap water, Electrochimica Acta 191 (2016) 548-557.

[31] K. Ogle, S. Weber, Anodic Dissolution of 304 Stainless Steel Using Atomic Emission Spectroelectrochemistry 147 (2000) 1770-1780.

[32] V. Shkirskiy, P. Marciel, J. Deconinck, K. Ogle, On the time resolution of the atomic emission spectroelectrochemistry method, Journal of the Electrochemical Society 163 (2016) C1-C8.

[33] C. Nobel, F. Klocke, D. Lung, S. Wolf, Machinability enhancement of lead-free brass alloys, Procedia CIRP 14 (2014) 95-100.

[34] C. Nobel, U. Hofmann, F. Klocke, D. Veselovac, H. Puls, Application of a new, severe-condition friction test method to understand the machining characteristics of $\mathrm{Cu}-$ Zn alloys using coated cutting tools, Wear 344 (2015), 58-68. 

selective corrosion of copper-zinc alloys for the drinking water installation, Materials and Corrosion 60 (2009) 251-258.

[36] M. A. Taha, T. M. Mousa, R. M. Hamouda, A. F. A. G. Yousef, Microstructure and castability of lead - free silicon brass alloys.Materialwissenschaft und Werkstofftechnik 43 (2012) 699-704.

[37] C. Ackfeld, O. von Franqué, W. Siedlarek, Elektrochemische untersuchungen von handelsüblichen kupferrohren mit verschiedenen oberflächenzuständen, Materials and Corrosion 48, 624-630. (in German)

[38] International Organization for Standardization, ISO 6509-1: 2014, Corrosion of metals and alloys - Determination of dezincification resistance of copper alloys with zinc - Part 1: Test method, 2014.

[39] International Organization for Standardization, ISO 6509-1: 2014, ISO 6509-2, Corrosion of metals and alloys - Determination of dezincification resistance of copper alloys with zinc - Part 2: Acceptance criteria, 2014.

[40] K. Ogle, M. Mokaddem, P. Volovitch, Atomic emission spectroelectrochemistry applied to dealloying phenomena II. Selective dissolution of iron and chromium during active-passive cycles of an austenitic stainless steel, Electrochimica Acta 55 (2010) 913921.

[41] J. C. Hamilton, J. C. Farmer, R. J. Anderson, In situ Raman spectroscopy of anodic films formed on copper and silver in sodium hydroxide solution, Journal of the Electrochemical Society 133 (1986) 739-745.

[42] L. Yohai, W.H. Schreiner, M. Vázquez, M. B. Valcarce, Surface characterization of copper: zinc and brass in contact with tap water inhibited with phosphate ions, Applied Surface Science 257 (2011) 10089-10095.

[43] M. Biton, G. Salitra, D. Aurbach, P. Mishkov, D. Ilzycer, On the electrochemical behavior and passivation of copper and brass $(\mathrm{Cu} 70 / \mathrm{Zn} 30)$ electrodes in concentrated aqueous KOH solutions, Journal of the Electrochemical Society 153 (2006) B555-B565. [44] F. Ospitali, C. Chiavari, C. Martini, E. Bernardi, F. Passarini, L. Robbiola, The characterization of Sn-based corrosion products in ancient bronzes: a Raman approach, Journal of Raman Spectroscopy 43 (2012) 1596-1603.

[45] P. L. Kazansky, Y. E. Pronin, I. A. Arkhipushkin, XPS study of adsorption of 2mercaptobenzothiazole on a brass surface, Corrosion Science 89 (2014) 21-29.

[46] M. H. Saber; A. A. El Warraky, Electrochemical and spectroscopic studies on dezincification of a-brass Part II. Effect of polarization on the dezincification process, Desalination 93 (1993) 473-486

[47] L. Yohai, W. H. Schreiner, M. Vázquez, M. B. Valcarce, Surface characterization of copper, zinc and brass in contact with tap water inhibited with phosphate ions, Applied Surface Science 257 (2011) 10089-10095.

[48] T. L. Barr, J. J. Hackenberg, Determination of the onset of the dezincification of alpha-brass using x-ray photoelectron (ESCA) spectroscopy, Journal of the American Chemical Society 104 (1982) 5390-5394.

[49] L. Bruce Railsback. Some Fundamentals of Mineralogy and Geochemistry. Georgia, 2006. 
[50] N. T. Rochman, K. Yamada, R. Fujimoto, S. I. Suehiro, H. Sueyoshi, Effects of microstructural factors and alloying elements on dezincification of brass, Journal of Advanced Science 13 (2001) 277-280.

[51] G. Joseph, M. T. Arce, Contribution to the study of brass dezincification, Corrosion Science 7 (1967) 597-605.

[52] V. F. Lucey, The mechanism of dezincification and the effect of arsenic. II, British

Corrosion Journal 1 (1965) 53-59.

\section{Table Captions}

Table 1. Composition of brass samples. 
Table 2. Steady state dissolution rate of brass alloys in STW (upper) and deaerated CBS (lower). 


\section{Tables}

Table 1 Compositions of brass samples

\begin{tabular}{ccccccccccccc}
\hline Alloy & $\mathrm{Cu}$ & $\mathrm{Si}$ & $\mathrm{P}$ & $\mathrm{Zn}$ & $\mathrm{Pb}$ & $\mathrm{Fe}$ & $\mathrm{Ni}$ & $\mathrm{Sn}$ & $\mathrm{Al}$ & \\
\hline CuZn42 & 57.5 & $<0.01$ & $<0.01$ & 42 & 0.17 & 0.12 & 0.01 & 0.27 & $<0.01$ & $<0.01$ \\
CuZn21Si3P & 75.8 & 3.06 & 0.05 & 21 & 0.05 & 0.02 & 0.01 & 0.01 & $<0.01$ & $<0.01$ \\
\hline
\end{tabular}

Table 2. Steady dissolution rate of brass alloys in STW (upper) and deaerated CBS (lower).

\begin{tabular}{|c|c|c|c|c|}
\hline & & $\mathrm{Zn}$ & $\mathrm{Cu}$ & $\mathrm{Cu}$ (congruent) \\
\hline & & $\mathrm{pmol} \mathrm{s}^{-1}$ & \multicolumn{2}{|c|}{$\mathrm{pmol} \mathrm{s}^{-1}$} \\
\hline \multirow{2}{*}{ STW } & $\mathrm{CuZn} 42$ & $9.59 \pm 5.22$ & $0.60 \pm 0.85$ & 13.43 \\
\hline & CuZn21Si3P & $5.22 \pm 1.02$ & $1.67 \pm 1.11$ & 18.84 \\
\hline \multirow{4}{*}{ CBS } & CuZn42 reference & $1.82 \pm 2.11$ & $2.32 \pm 0.78$ & 2.55 \\
\hline & $\mathrm{CuZn} 42$ & $3.28 \pm 1.68$ & $5.40 \pm 0.78$ & 4.59 \\
\hline & CuZn21Si3P reference & $1.39 \pm 1.83$ & $3.13 \pm 0.92$ & 5.13 \\
\hline & $\mathrm{CuZn21Si3P}$ & $1.65 \pm 0.69$ & $6.98 \pm 1.28$ & 6.09 \\
\hline
\end{tabular}

29

30

31

\section{Figure Captions}

Fig. 1 Optical microscope observation of the dezincification structure of $\mathrm{CuZn} 42$ (upper) and CuZn21Si3P (lower) following an ISO 6509 dezincification test. The red defect-rich structure on the cross section is the dezincification structure. 
Fig. 2 STW-CBS experiment of CuZn42 (A) and CuZn21Si3P (B) at $i_{a p}=80 \mu \mathrm{A}$. a: open circuit in STW for $300 \mathrm{~s}$; b: galvanostatic dissolution in STW at $80 \mu \mathrm{A}$ for $1200 \mathrm{~s}$; c: open circuit in STW for $300 \mathrm{~s}$; d: open circuit in CBS for $1500 \mathrm{~s}$.

Fig. 3. Enlarged view of the open circuit dissolution transient of $\mathrm{CuZn} 42$ (A) and CuZn21Si3P (B).

Fig. 4. Elemental dissolution of CuZn42 (A) and CuZn21Si3P (B) in exposure to STW. Upper: dissolution of $\mathrm{Cu}$; lower: dissolution curve of $\mathrm{Zn}$. Curves from upper to lower in $\mu \mathrm{A} \mathrm{cm}{ }^{-2}: 80,60,40,20,10,5,0$.

Fig. 5. Superimposition of residual film dissolution of CuZn42 (A) and CuZn21Si3P (B) in CBS. Captions a $-\mathrm{g}$ : a: fresh brass exposed to CBS; $\mathrm{b}-\mathrm{g}$ represents $i_{a p} / \mu \mathrm{A} \mathrm{cm}{ }^{-2}=0$, $5,10,20,40$ and 80 respectively.

Fig. 6. GIXRD results of CuZn 42 and CuZn21Si3P after exposure to STW at $i_{a p}=80 \mu \mathrm{A}$ $\mathrm{cm}^{-2}$.

Fig. 7. Raman spectra of CuZn42 (A) and CuZn21Si3P (B) after exposure to synthetic tap water at different anodic current.

Fig. 8. SEM observation of the surface topography of $\mathrm{CuZn} 42$ being anodically polarized in STW. $i_{a p}=5 \mu \mathrm{A} \mathrm{cm}^{-2}, t=1200 \mathrm{~s}$.

Fig. 9. SEM observation of the surface topography of CuZn21Si3P being anodically polarized in STW. $i_{a p}=5 \mu \mathrm{A} \mathrm{cm}^{-2}, t=1200 \mathrm{~s}$.

Fig. 10. Comparison between $\mathrm{Q}_{\mathrm{e}}$ (pstat) and $\mathrm{Q}_{\mathrm{e}}(\mathrm{ICP})$ for $\mathrm{CuZn} 42(\Delta)$ and CuZn21Si3P ( $\square$ ) respectively as a function of applied current (A) and as a function of time duration (B).

Fig. 11. The increase of soluble species $\left(Q_{C u(a q)}(S T W)\right)$ and insoluble species $\left(Q_{C u(a q)}(C B S)\right)$ as a function of applied current for CuZn42 and CuZn21Si3P.

Fig. 12. Thickness calculation of $\mathrm{Cu}_{2} \mathrm{O}$ layer and dezincified layer, and dezincification factor ( $Z$ factor) as a function of applied current.

Fig. 13. Kinetic analysis of elemental dissolution, oxide film and the dezincified pure copper layer growth of CuZn42 (A) and CuZn21Si3P (B) at $i_{a p}=40 \mu \mathrm{A} \mathrm{cm}^{-2}$. Dashed line represents the hypothetical curve for a step function after correcting for AESEC time constant. 


\section{Nomenclature:}

LOD limit of detection for a specific element $\left(\mu \mathrm{g} \mathrm{mL} \mathrm{L}^{-1}\right)$

STW synthetic tap water

CBS citrate buffer solution

A reaction area of the sample $\left(\mathrm{cm}^{2}\right)$

$f \quad$ flow rate $\left(\mathrm{mL} \mathrm{s}^{-1}\right)$

$i_{a p} \quad$ applied current during anodization experiment $\left(\mathrm{nA} \mathrm{cm}^{-2}\right)$

E potential (V vs. SCE)

$t \quad$ time (s)

F $\quad$ Faradaic constant $\left(=96500 \mathrm{C} \mathrm{mol}^{-1}\right)$

$\tau \quad$ empirical parameter for log-normal fit (s)

$\beta \quad$ empirical parameter for log-normal fit (no unit)

$v_{e} \quad$ applied current expressed as transfer rate of electrons $\left(\mathrm{nmol} \mathrm{s} \mathrm{cm}^{-1}\right.$ )

$v_{e}^{*} \quad v_{e}$ convoluted $\left(\mathrm{nmol} \mathrm{s} \mathrm{cm}^{-2}\right)$

$n$ stoichiometry factor of $\mathrm{Cu}$ (no unit)

$v_{\mathrm{Zn}(\mathrm{aq}),} \quad$ dissolution rate of soluble $\mathrm{Zn}$ species in STW $\left(\mathrm{nmol} \mathrm{s}^{-1} \mathrm{~cm}^{-2}\right)$

$v_{\mathrm{Cu}(\mathrm{aq})} \quad$ dissolution rate of soluble Cu species in STW $\left(\mathrm{nmol} \mathrm{s}^{-1} \mathrm{~cm}^{-2}\right)$

$v_{\Sigma} \quad$ sum of dissolution rate of soluble $\mathrm{Cu}$ and $\mathrm{Zn}$ in STW $\left(\mathrm{nmol} \mathrm{s} \mathrm{cm}^{-2}\right)$

$Q_{e}$ (pstat) the quantity of electricity obtained by integrating the current transient $\left.(\mathrm{nmol} \mathrm{cm})^{-2}\right)$

$Q_{e}(I C P) \quad$ the quantity of electricity obtained by calculating the electrochemical reaction assuming a known reaction factor $\left(\mathrm{nmol} \mathrm{cm} \mathrm{cm}^{-2}\right)$

$n_{m, a q} \quad$ stoichiometry factor of aqueous species for $\mathrm{Cu}, \mathrm{Zn}$ or $\mathrm{Si}$ (no unit)

$n_{m, s} \quad$ stoichiometry factor of solid species for $\mathrm{Cu}, \mathrm{Zn}$ or $\mathrm{Si}$ (no unit)

$Q_{m, a n} \quad$ the quantity of elemental dissolution of a metal, $m(\mathrm{Cu}, \mathrm{Zn}$ and $\mathrm{Si})$, contributed to either aqueous species $(a q)$ or solid species $\left.(\mathrm{s})(\mathrm{nmol} \mathrm{cm})^{-2}\right)$

$Q_{m}(S T W)\left(i_{a p}=0\right) \quad$ total quantity of elemental dissolution in STW during open circuit $\left(\mathrm{nmol} \mathrm{cm}{ }^{-2}\right.$ )

$Q_{m}(C B S)\left(i_{a p}=0\right) \quad$ total quantity of elemental dissolution in CBS during open circuit $\left(\mathrm{nmol} \mathrm{cm}{ }^{-2}\right)$

$Q_{m}(S T W)$ total quantity of elemental dissolution in STW during anodization $\left(\mathrm{nmol} \mathrm{cm} \mathrm{cm}^{-2}\right)$. $Q_{m}(C B S)$ total quantity of elemental dissolution in CBS during anodization $\left(\mathrm{nmol} \mathrm{cm} \mathrm{cm}^{-2}\right)$.

$\delta_{C u} \quad$ thickness of dezincified layer (nm)

$\delta_{\mathrm{Cu} 2 \mathrm{O}} \quad$ thickness of oxide layer $(\mathrm{nm})$

$\mathrm{M}_{\mathrm{Cu}} \quad$ atomic weight of $\mathrm{Cu}\left(\mathrm{g} \mathrm{mol}^{-1}\right)$

$\rho_{\mathrm{Cu}} \quad$ density of $\mathrm{Cu}\left(8.90 \mathrm{~g} \mathrm{~cm}^{-3}\right)$

$\mathrm{M}_{\mathrm{Cu} 2 \mathrm{O}} \quad$ atomic weight of $\mathrm{Cu}_{2} \mathrm{O}\left(\mathrm{g} \mathrm{mol}^{-1}\right)$ 


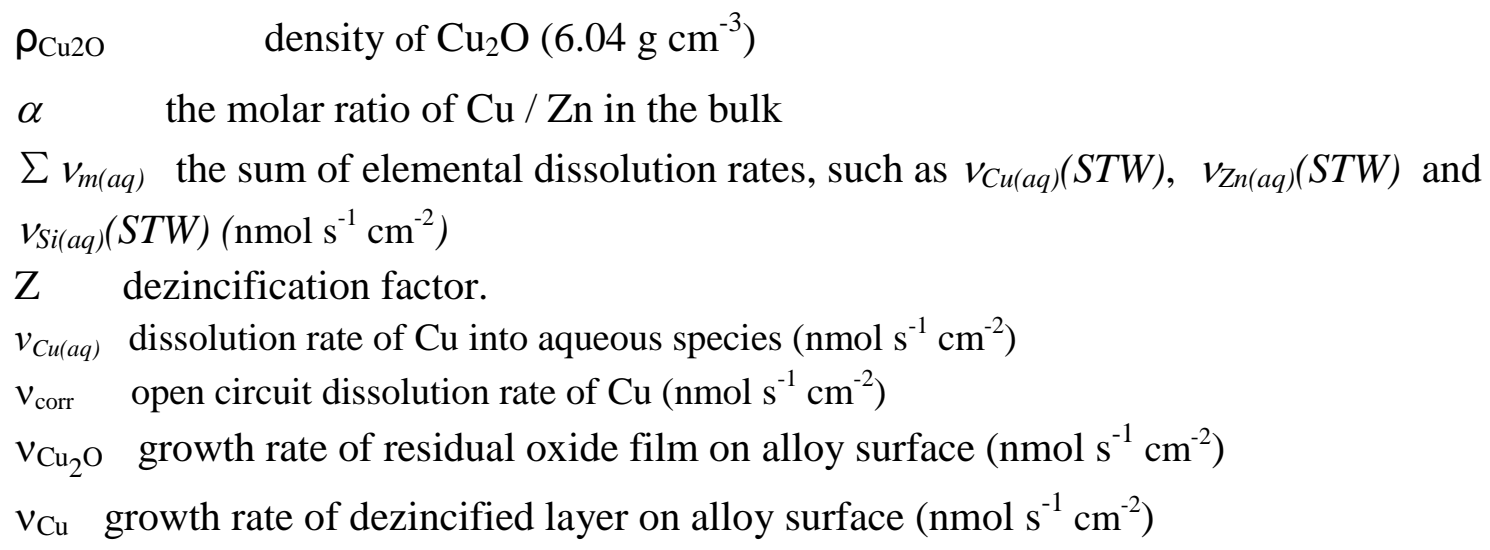


Fig. 1
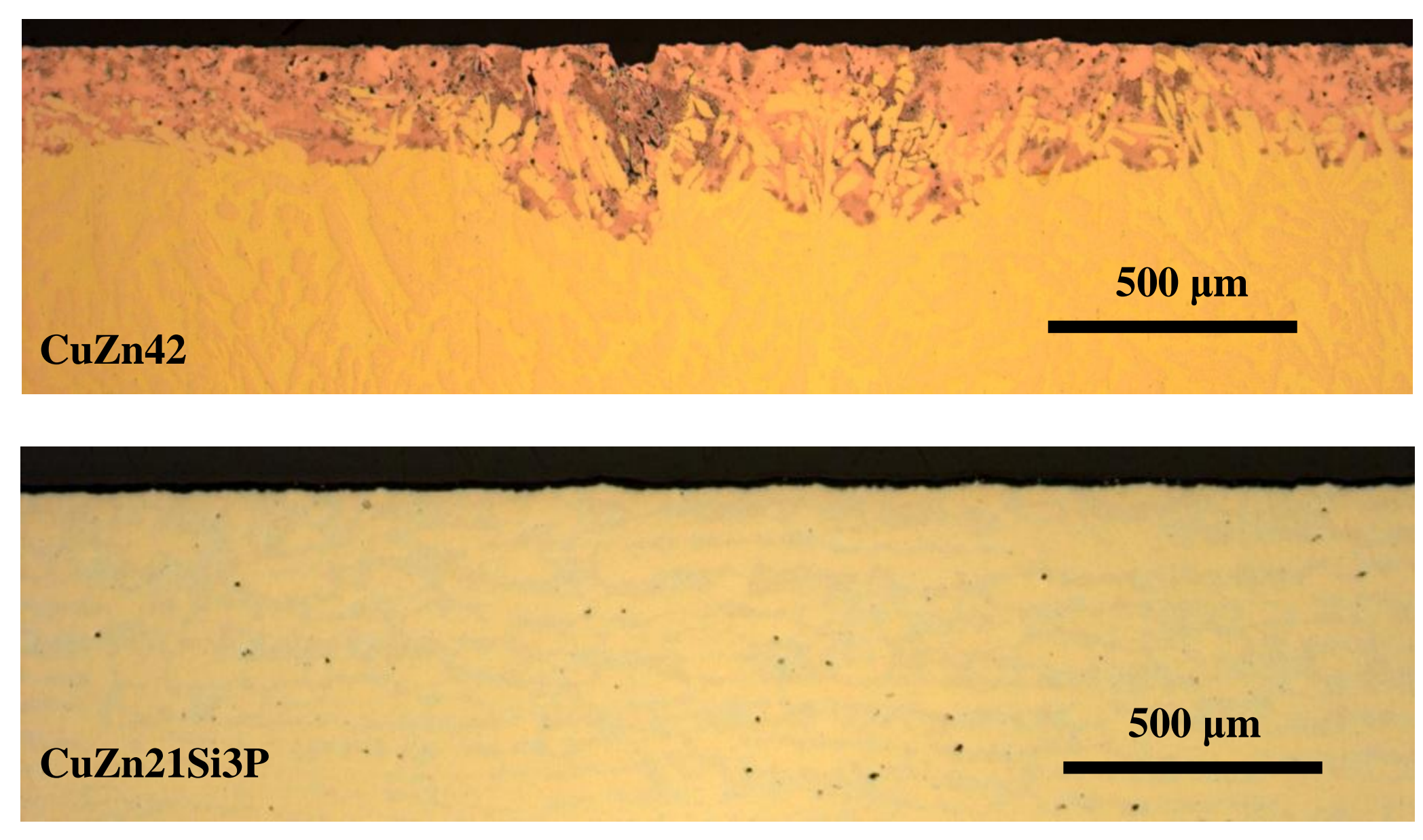
Fig. 2

(A)

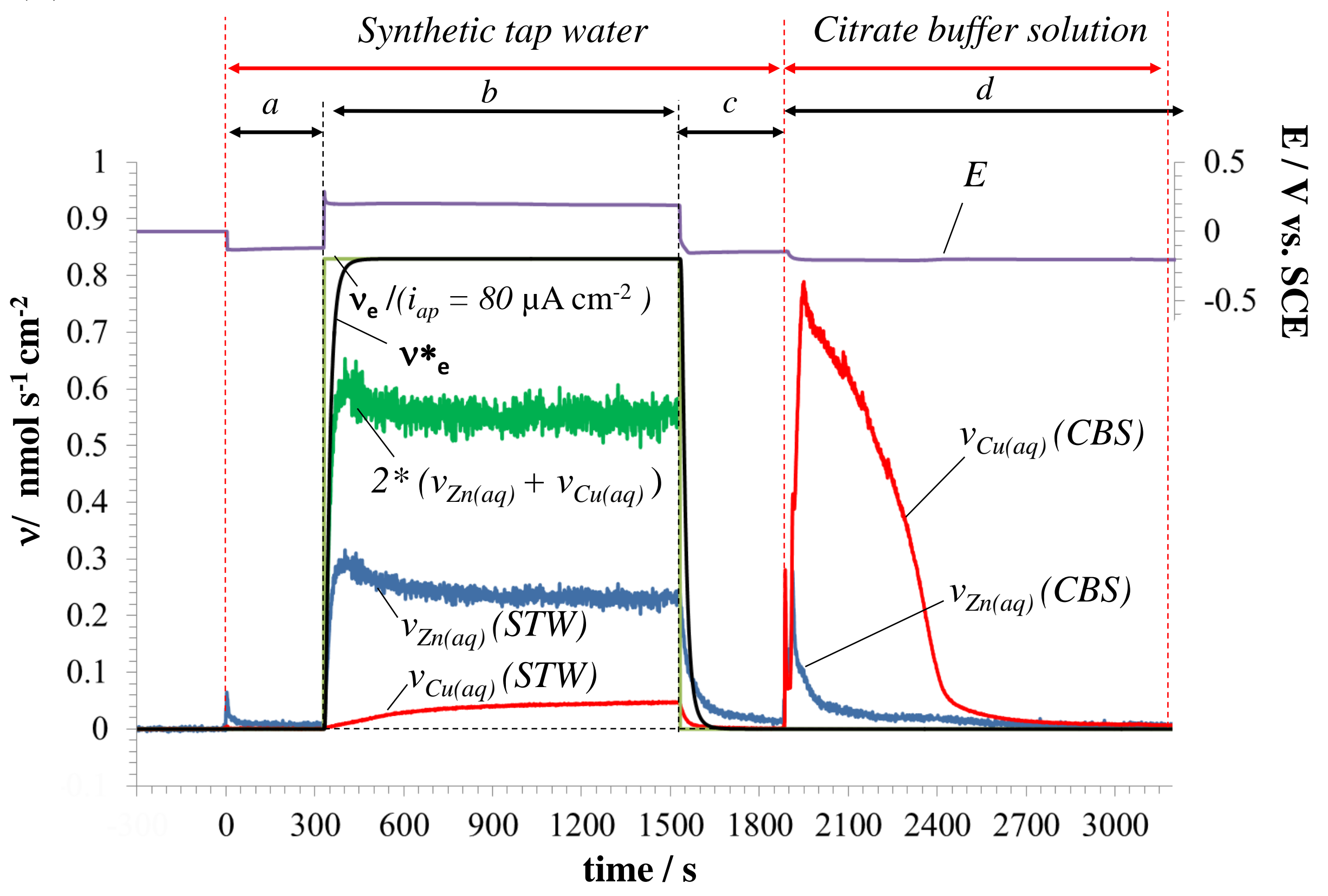


Fig. 2

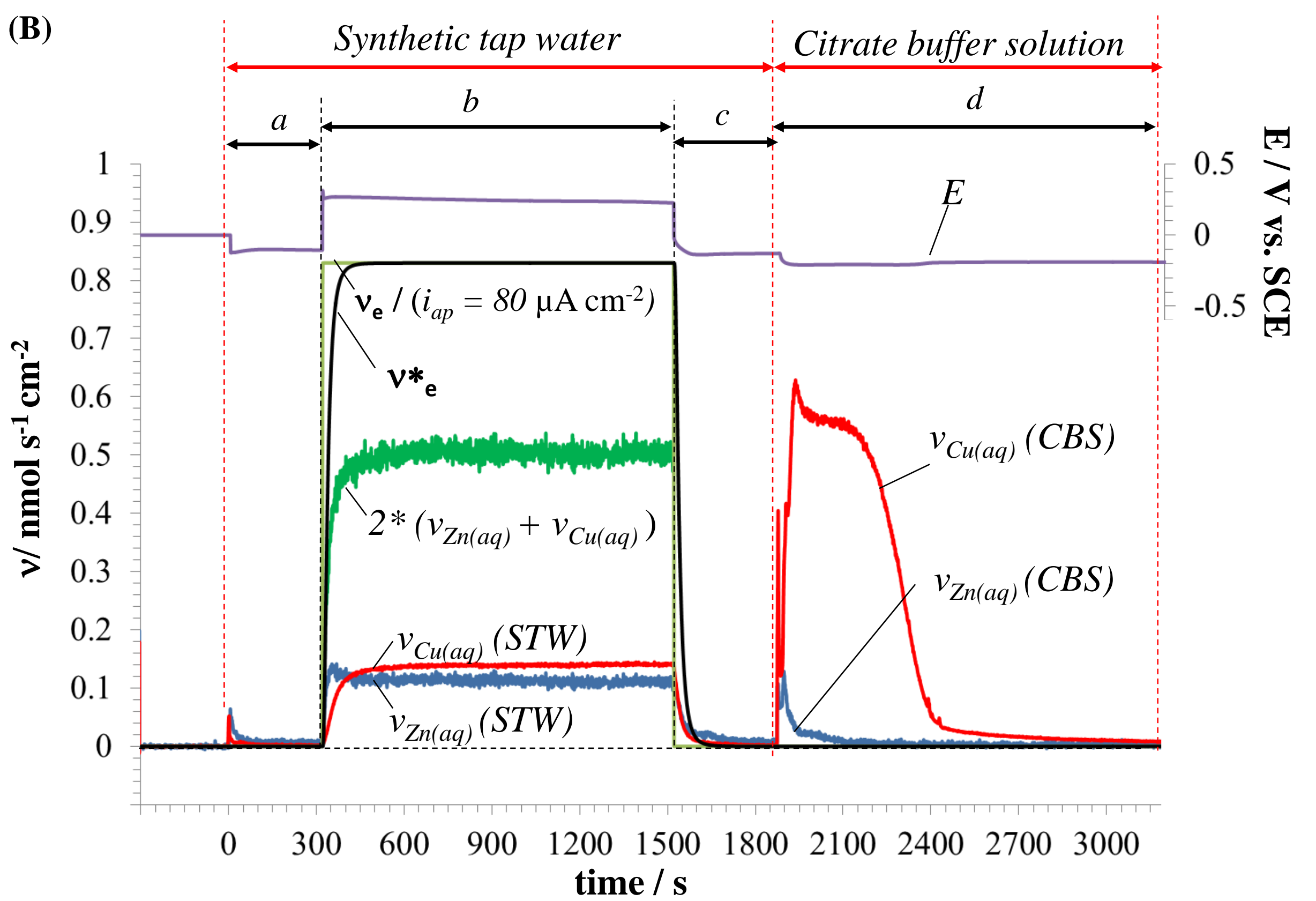


Fig. 3

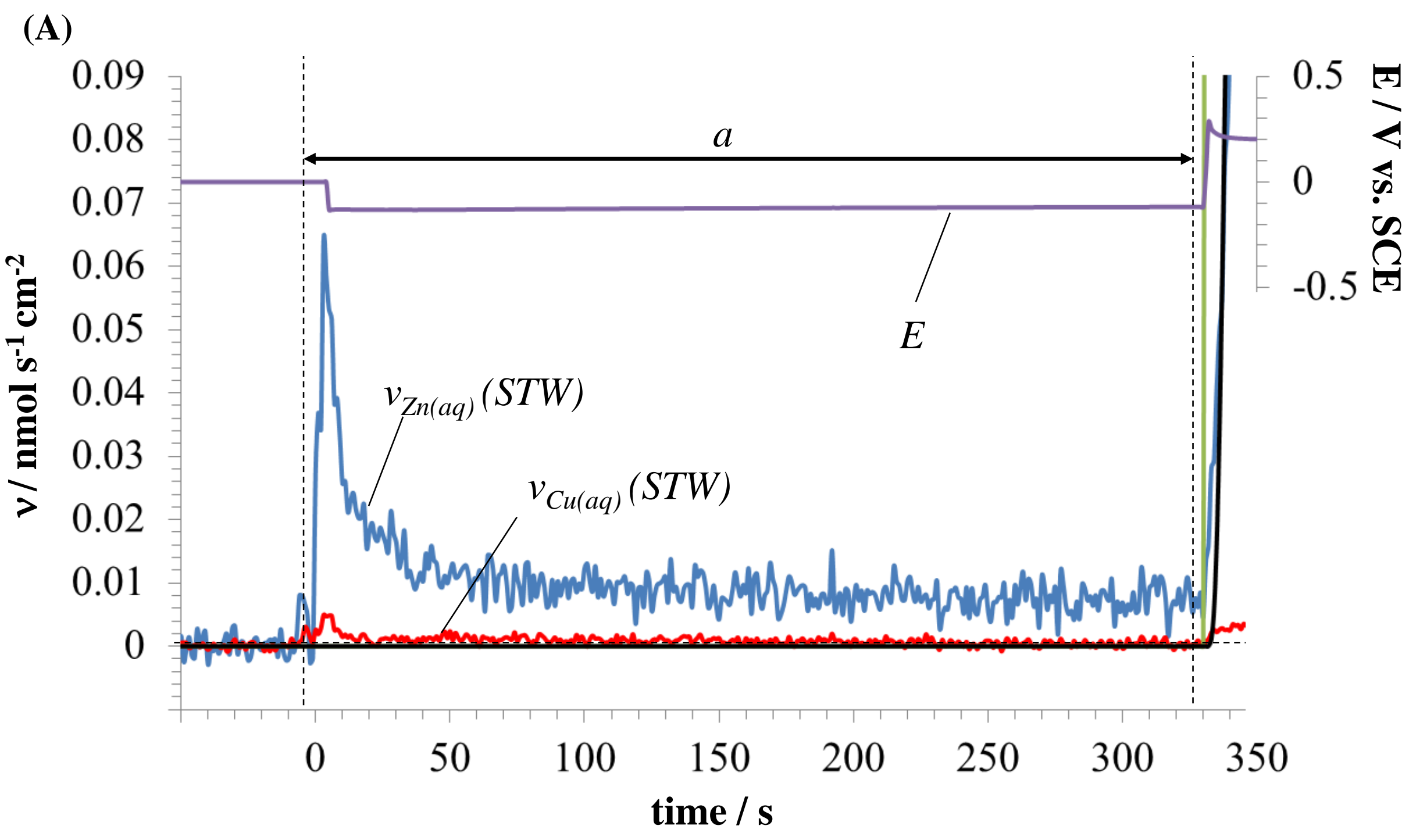


(B)

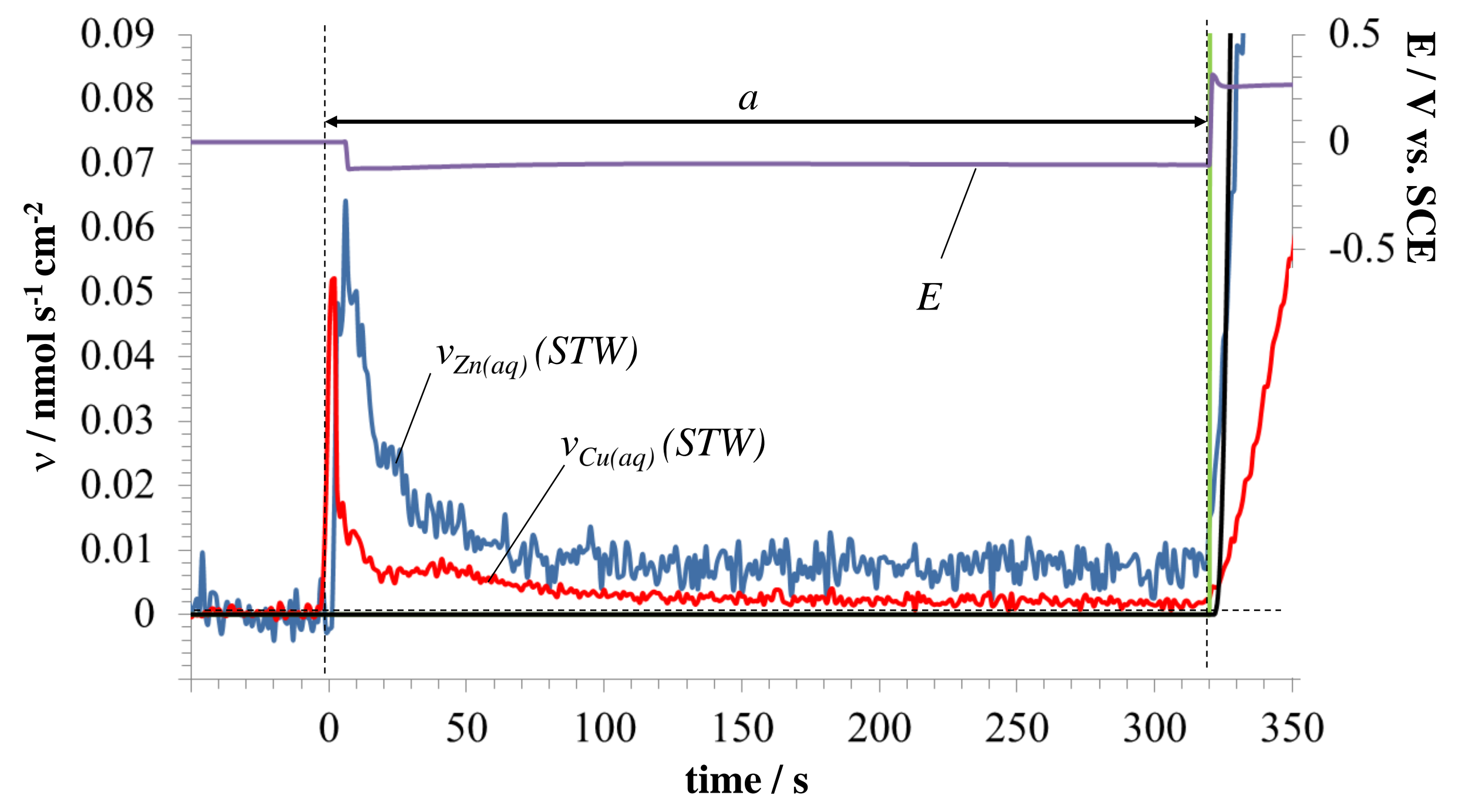


Fig. 4

(A)

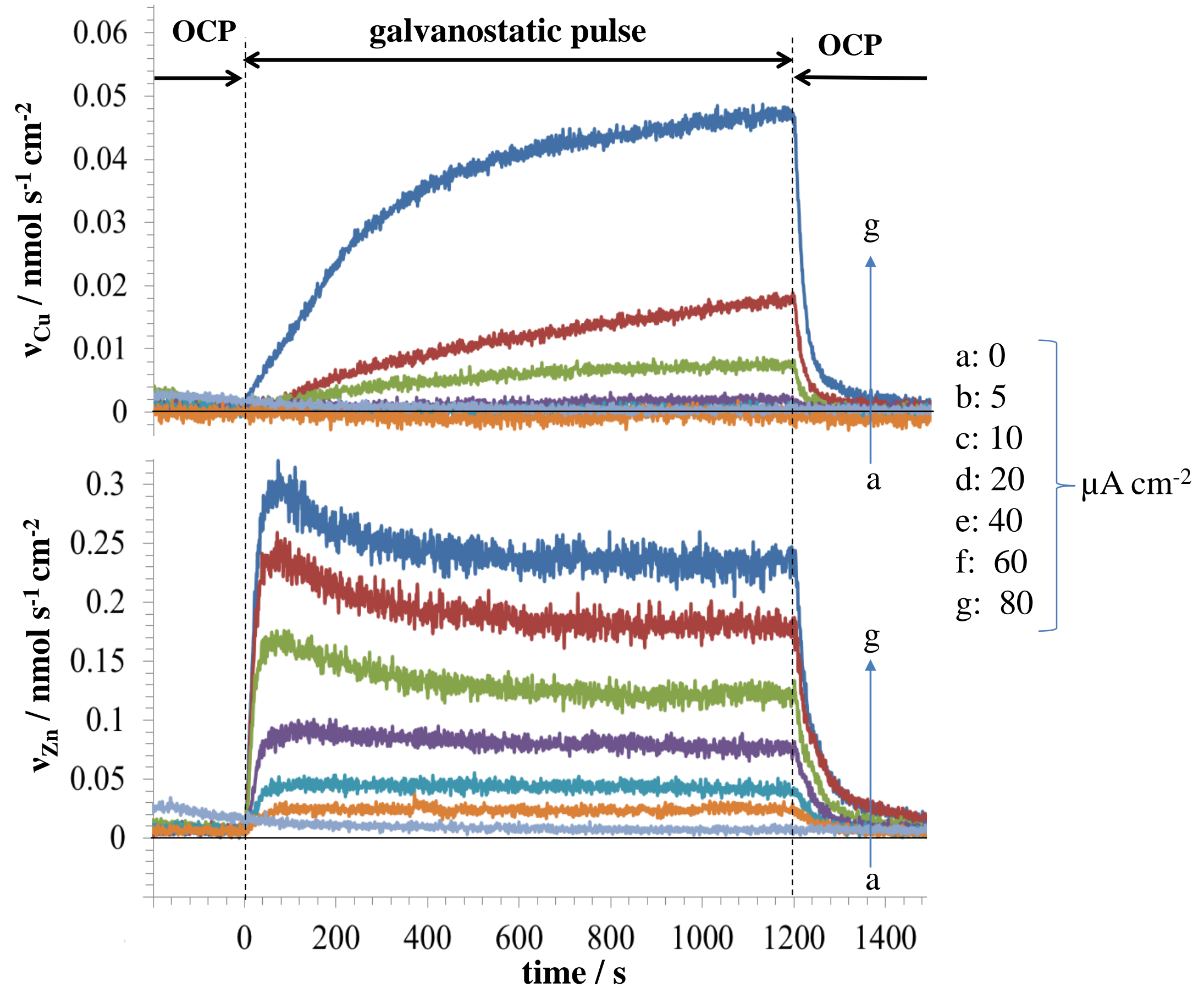


Fig. 4

(B)

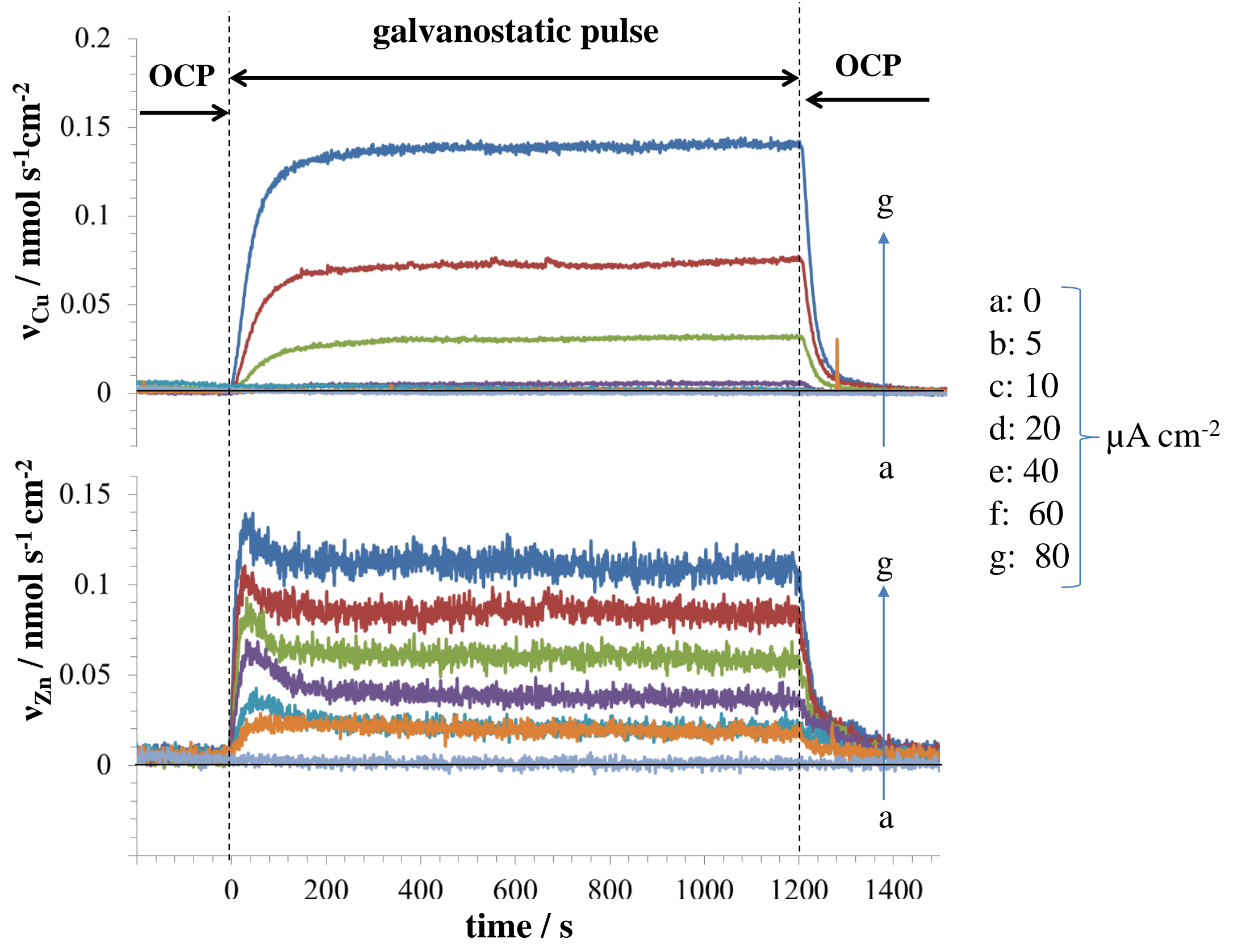


(A)

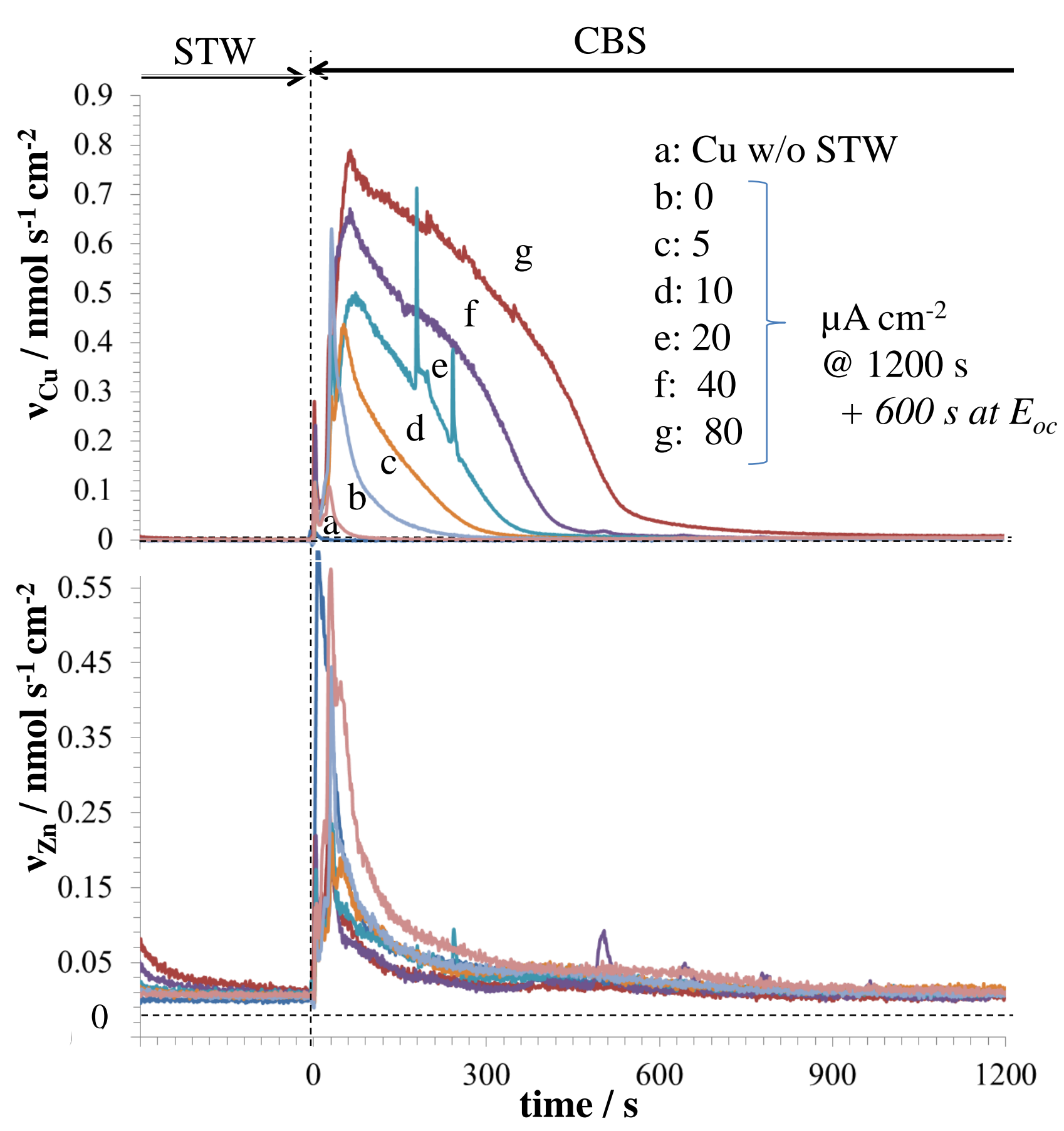

Fig. 5 


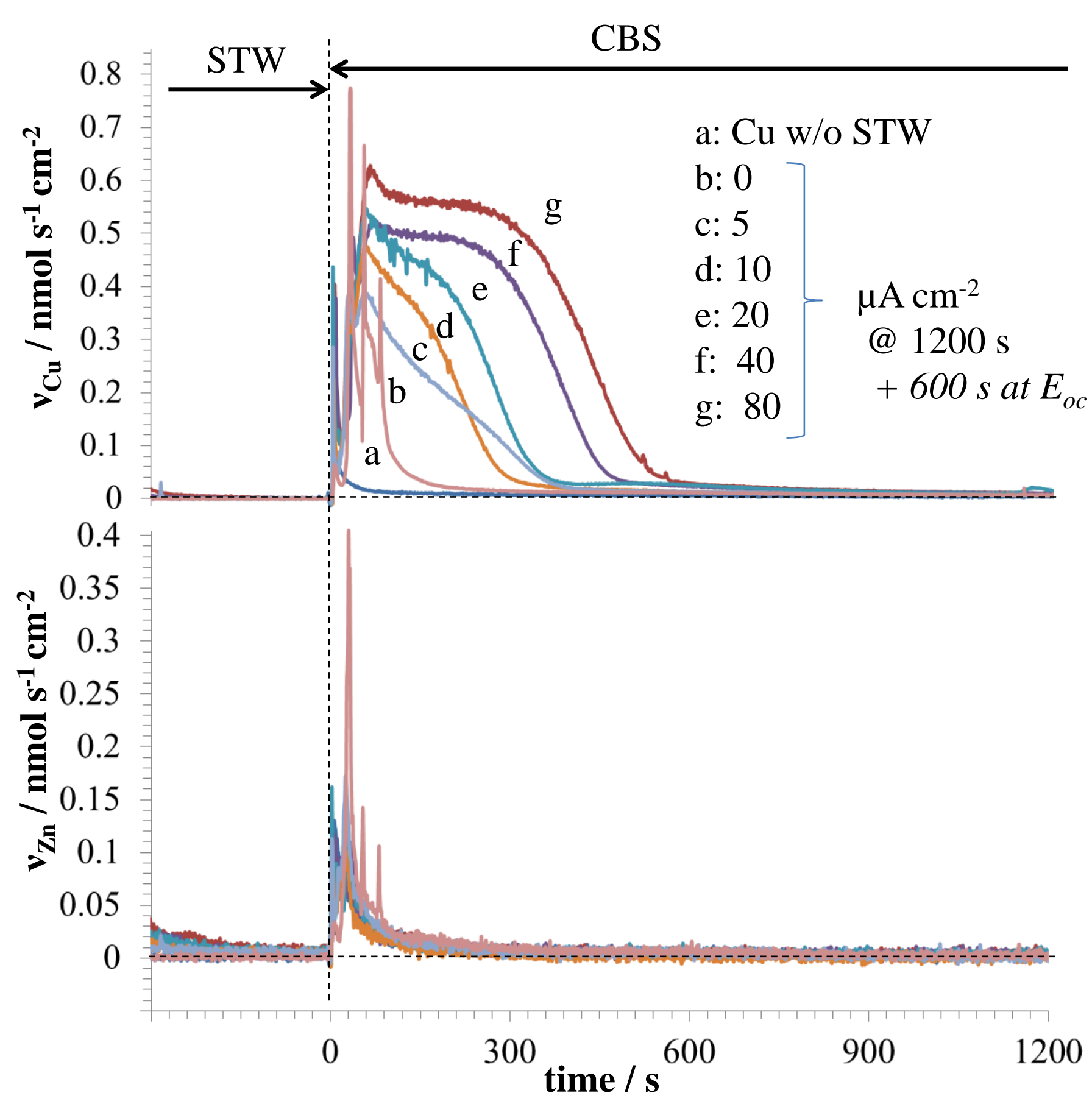

Fig. 5

c. 5

d: 10

e: 20

$\mu \mathrm{Acm}^{-2}$

f: 40

1200

+600 s at $E_{o c}$ 
Fig. 6

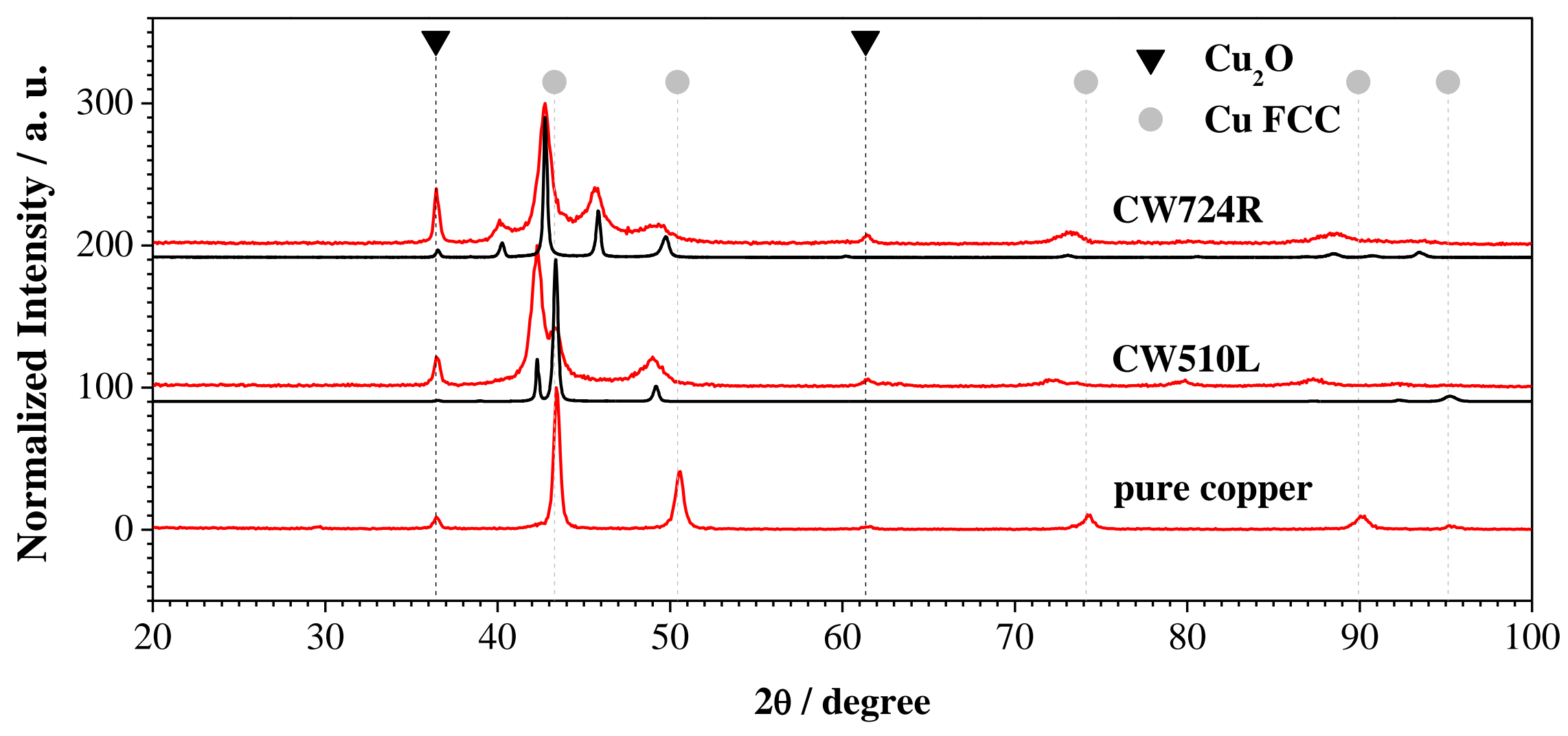




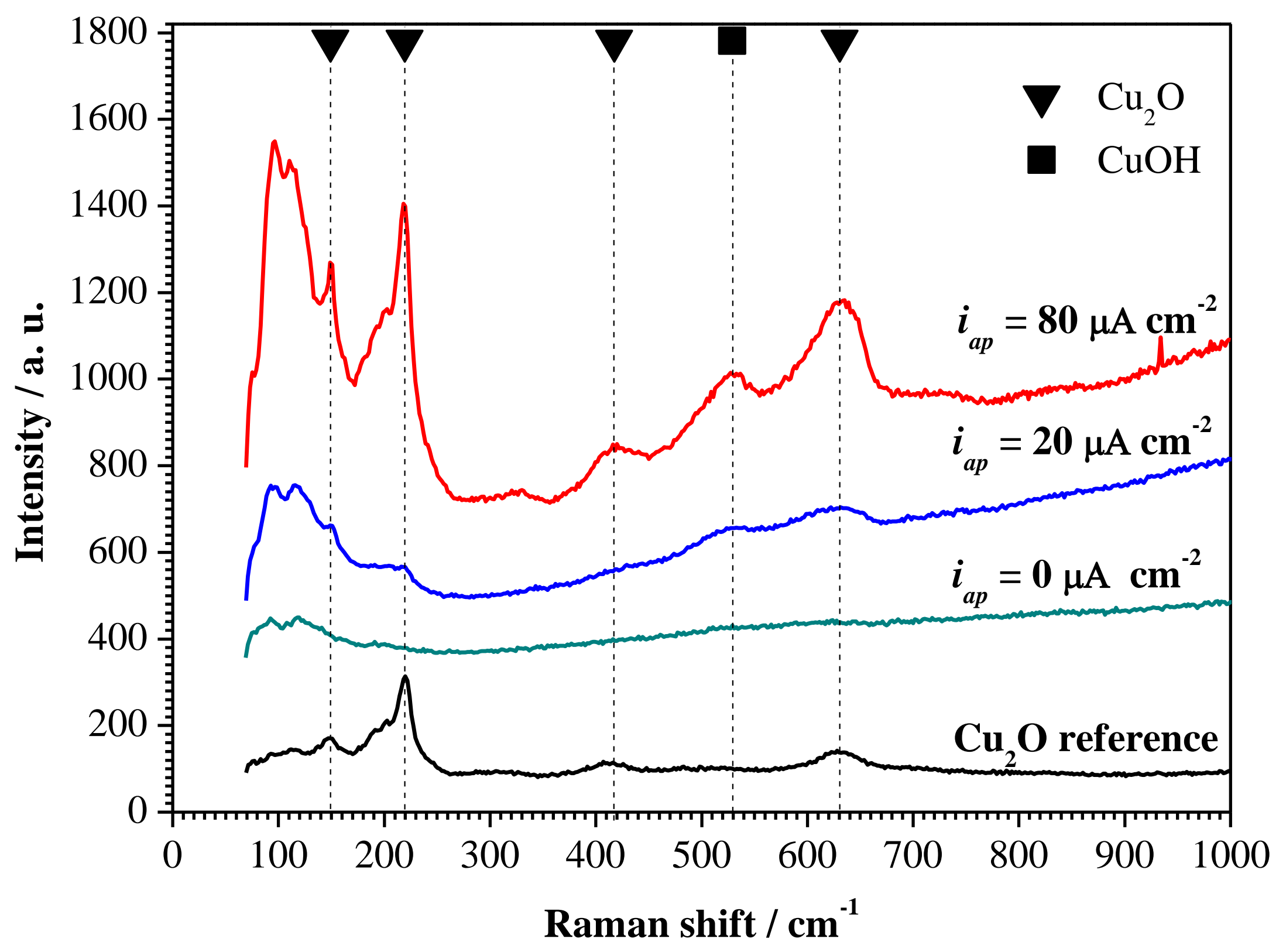




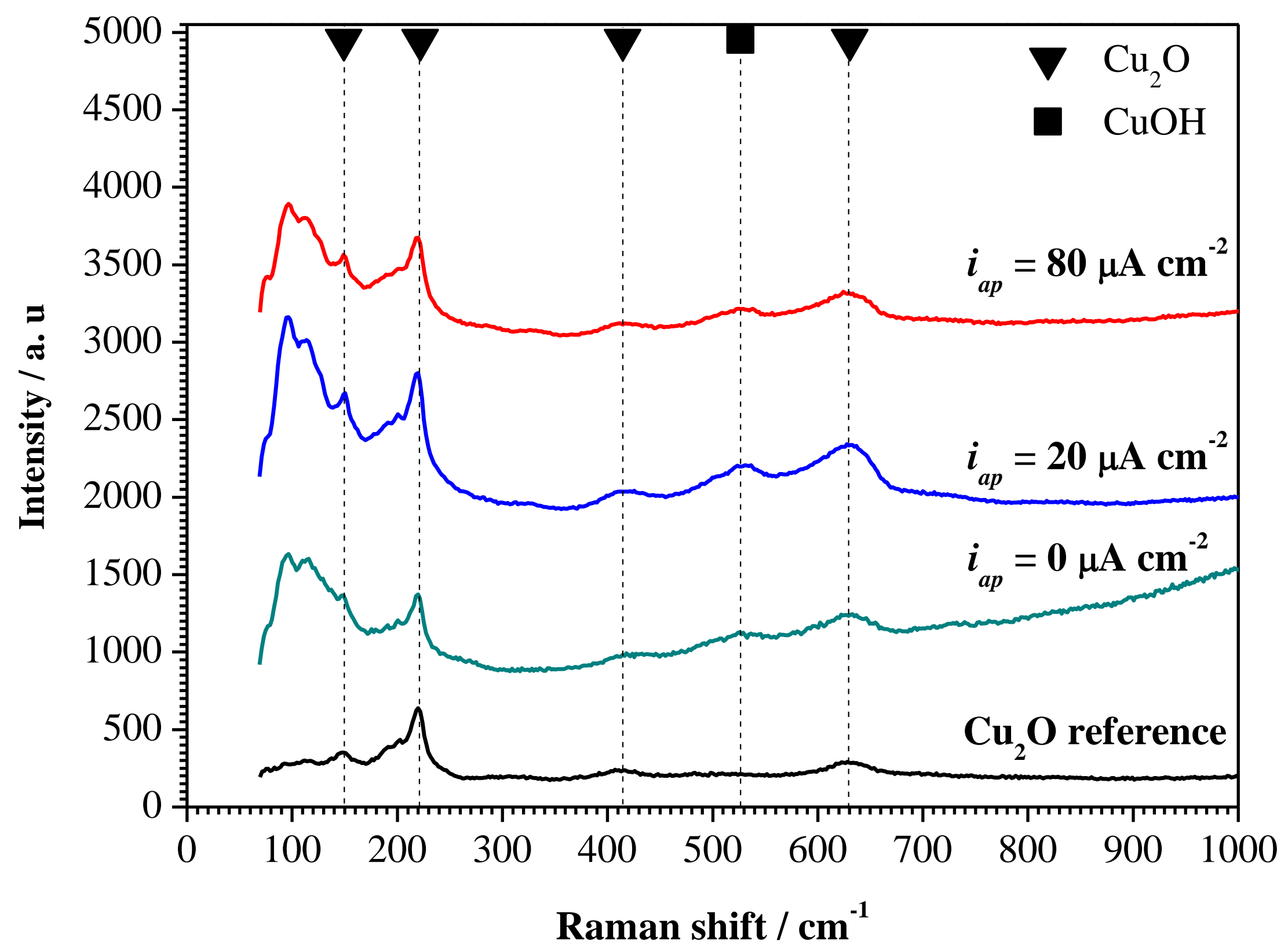


Fig. 8
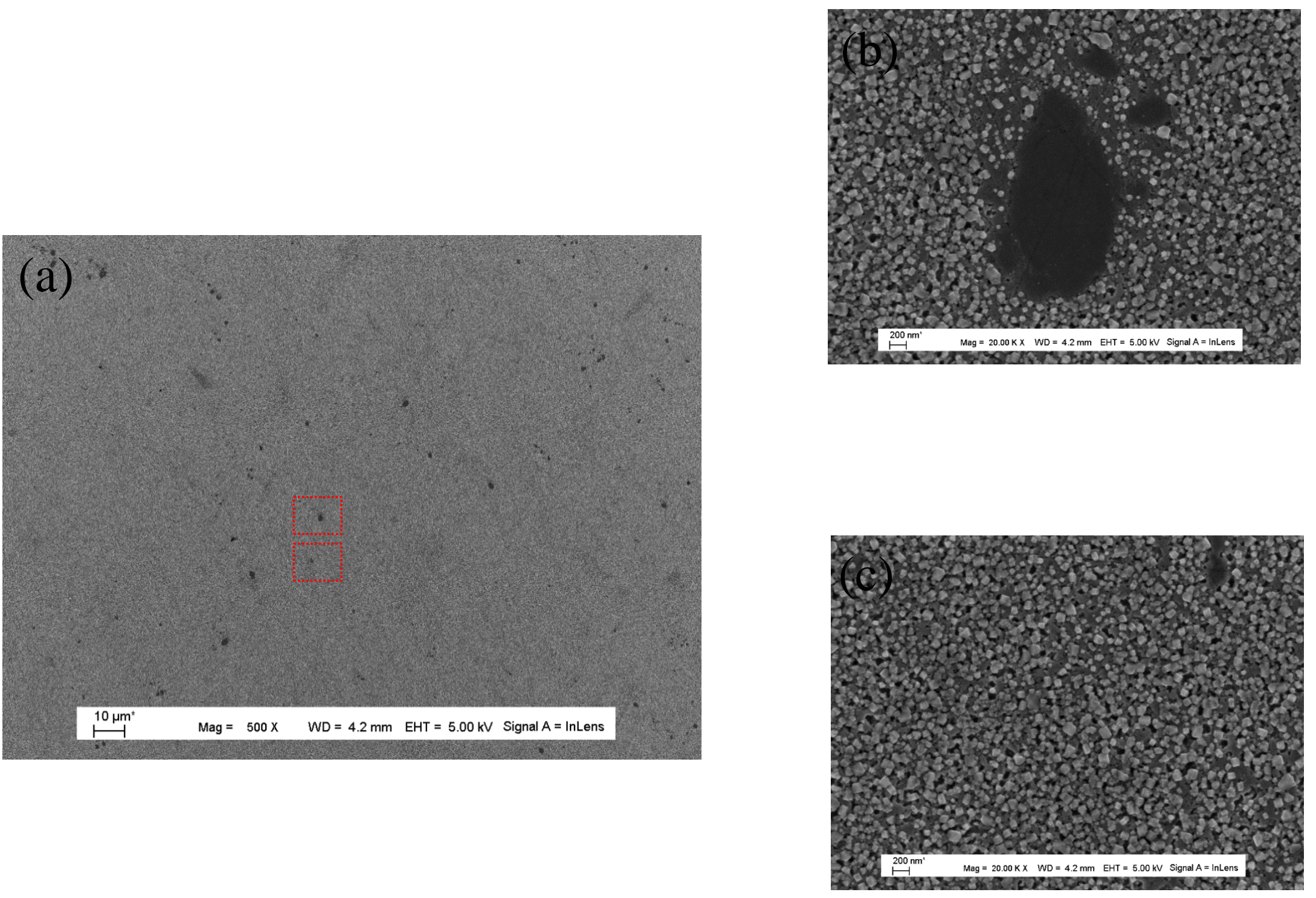
Fig. 9
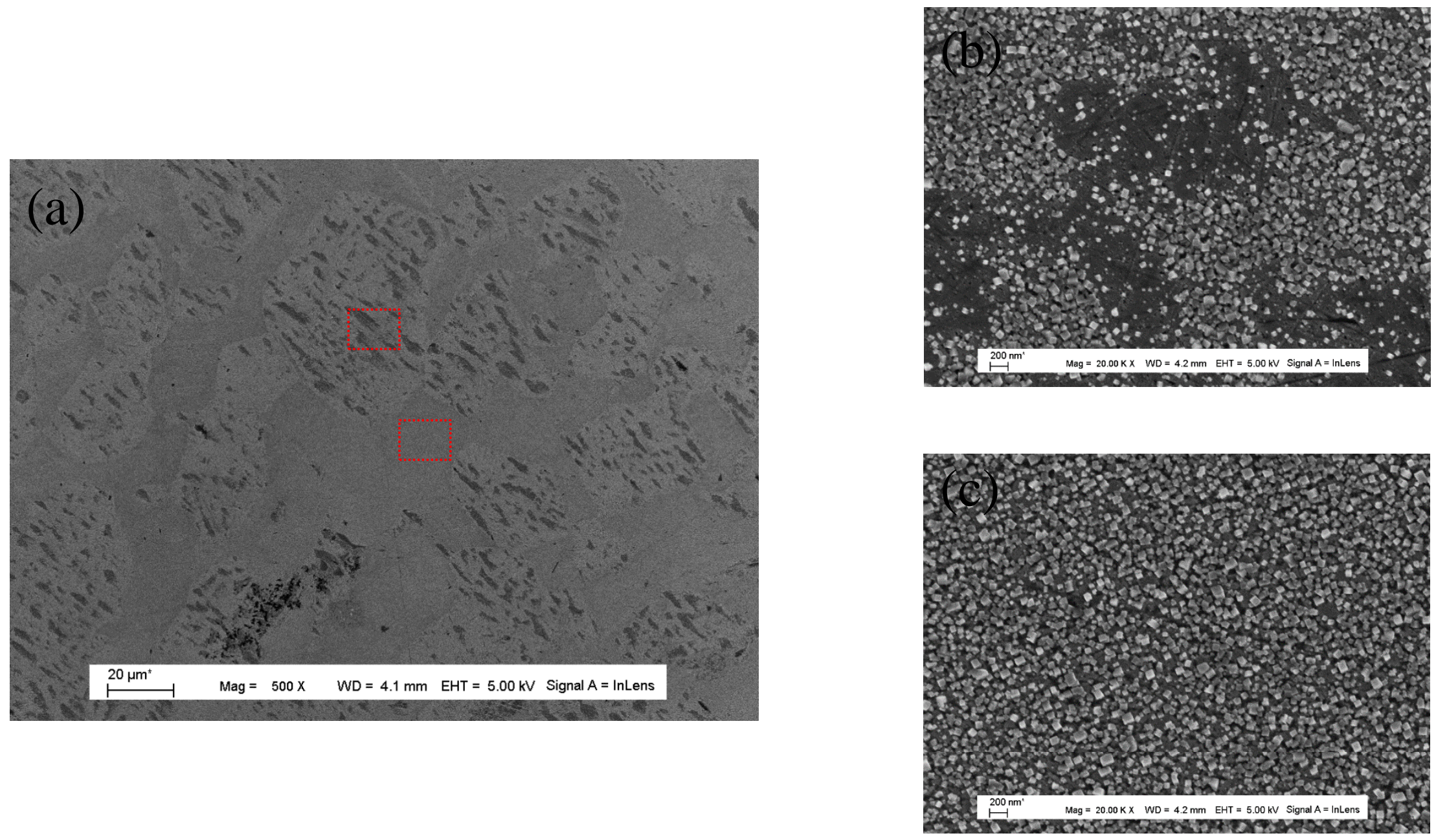
(A)

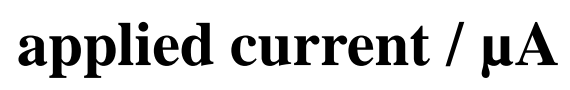

Fig. 10

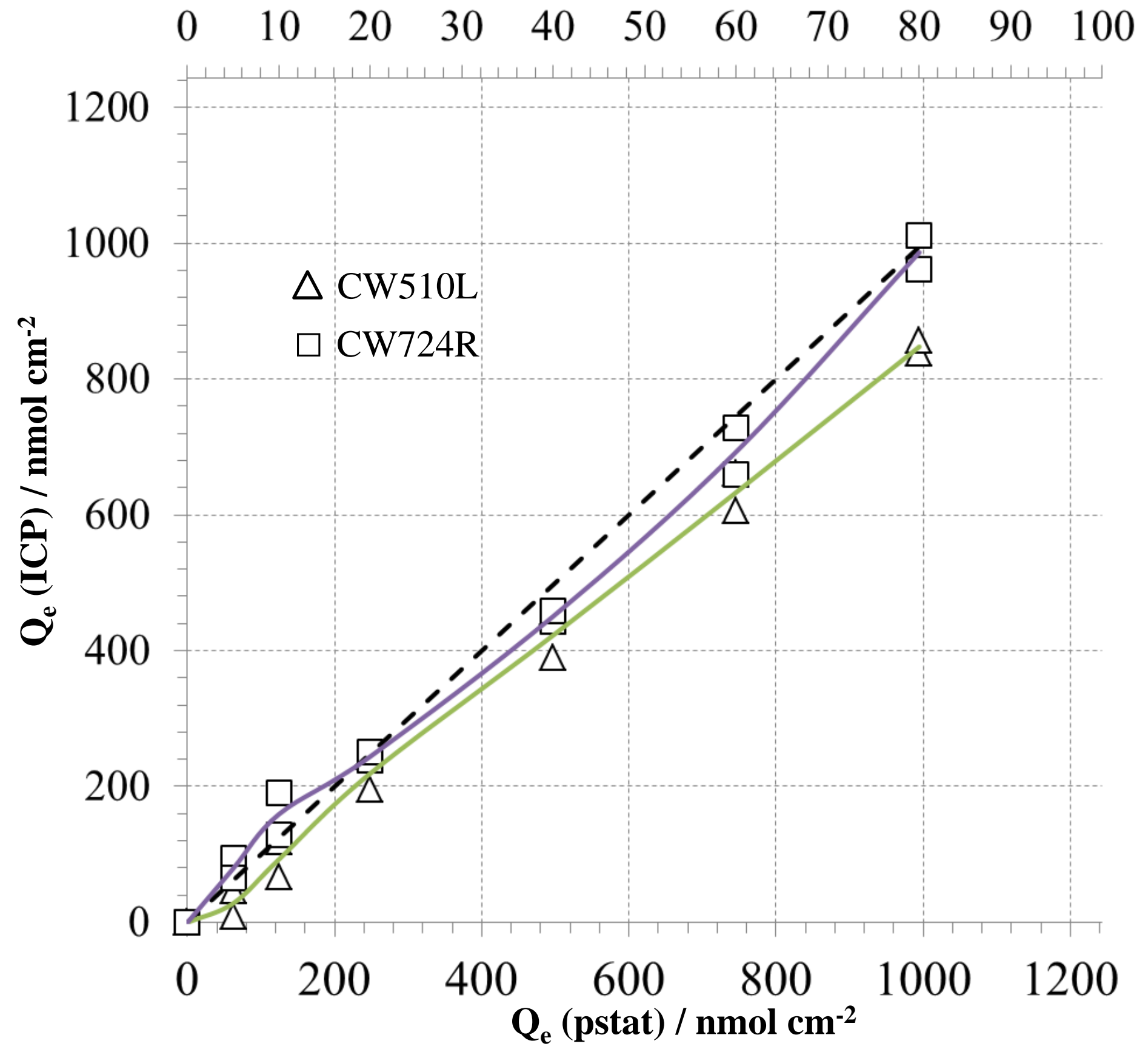


Fig. 11

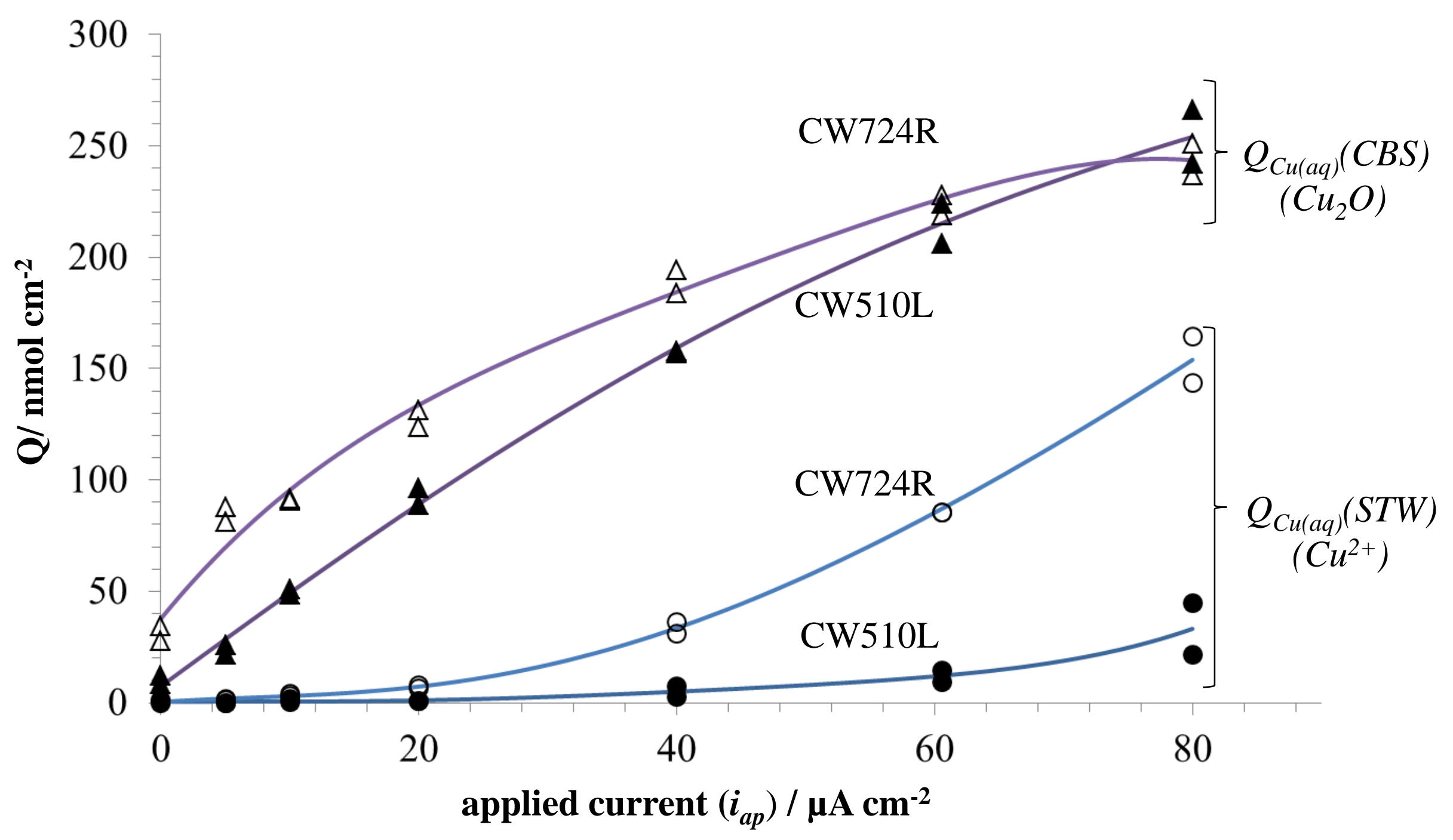


Fig. 12

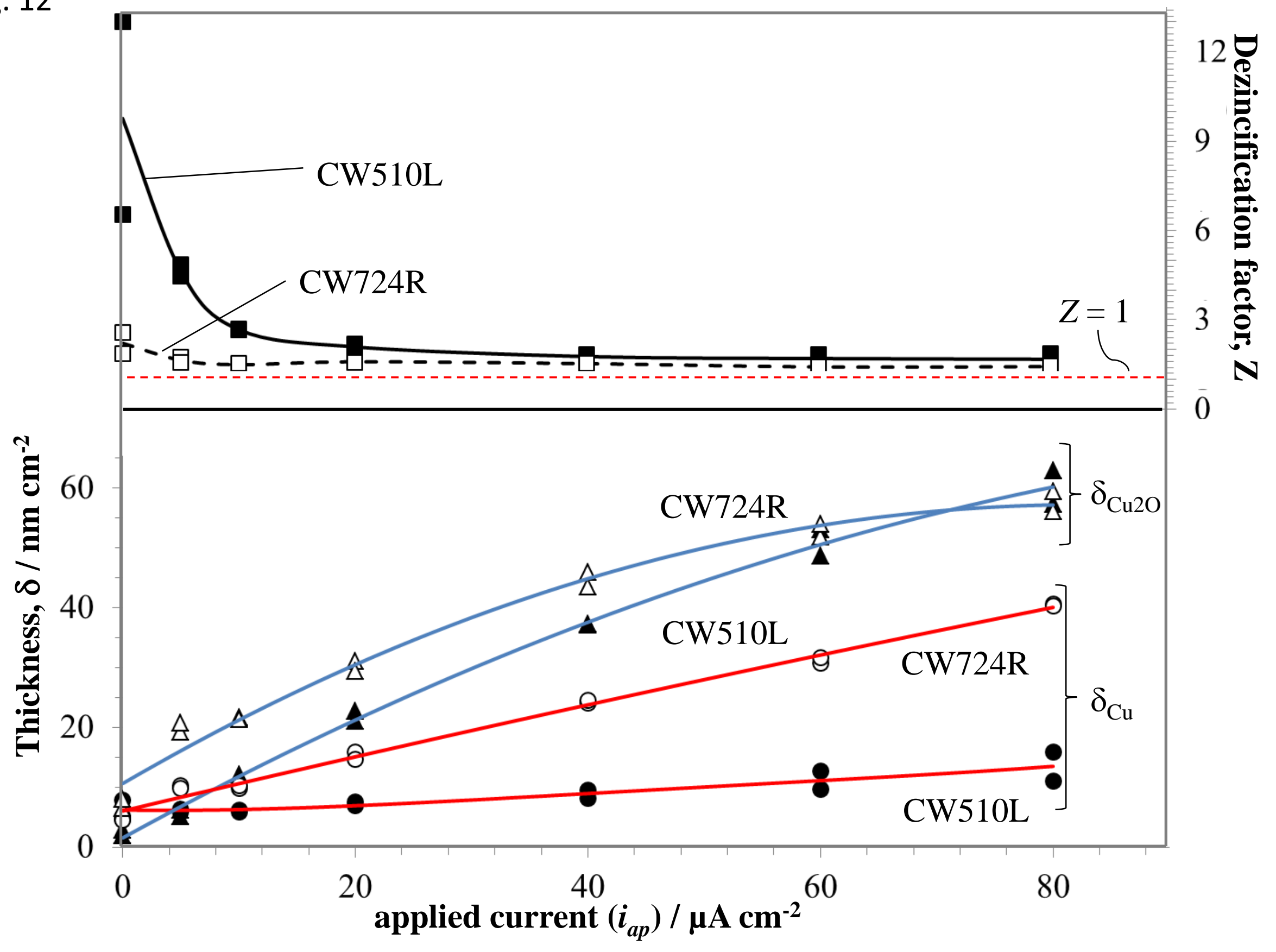


Fig. 13A
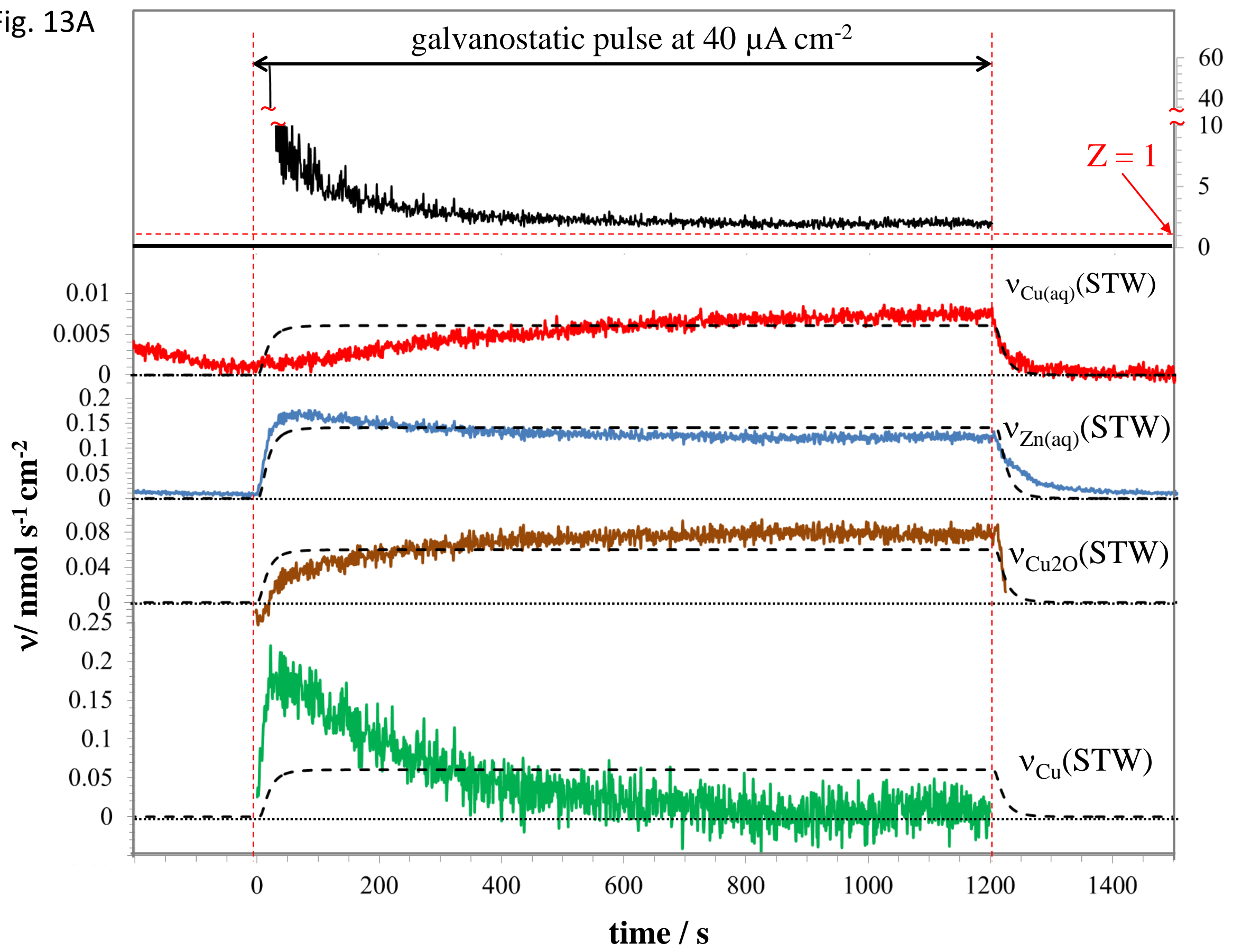
Fig. 13B

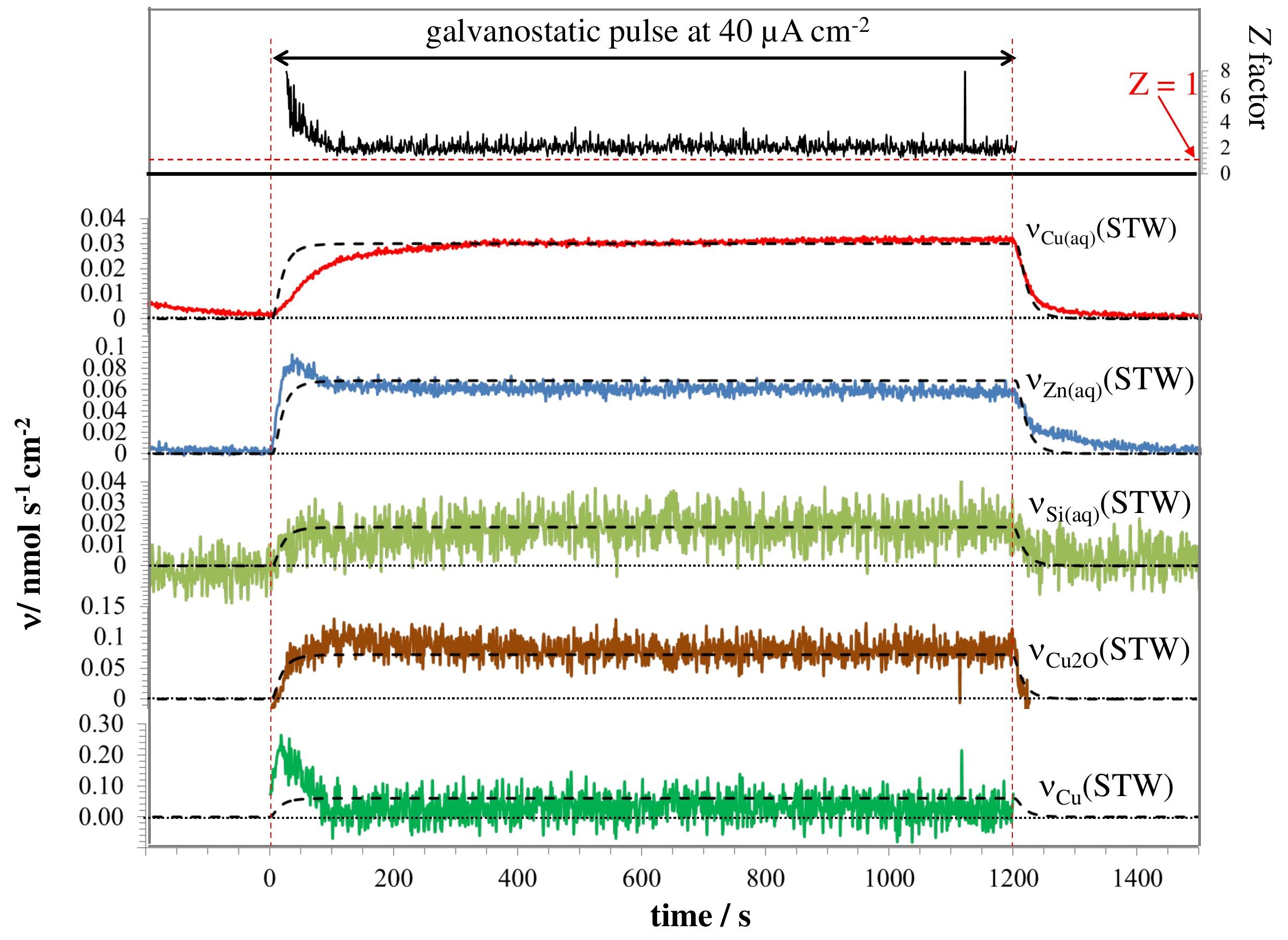

